\title{
HOW BAD IS INVOLUNTARY PART-TIME WORK?
}

Daniel Borowczyk-Martins Etienne Lalé

Discussion Paper 15 / 664

19 August 2015

Revised 13 January 2016

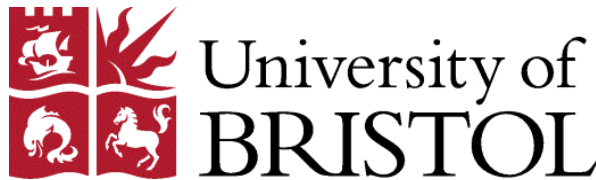

Department of Economics

University of Bristol

8 Woodland Road

Bristol BS8 1TN

United Kingdom 


\title{
How Bad is Involuntary Part-time Work?*
}

\author{
Daniel Borowczyk-Martins ${ }^{\dagger}$ \\ Sciences Po and IZA
}

\author{
Etienne Lalé $\ddagger$ \\ University of Bristol
}

This version: January 2016

\begin{abstract}
We use a set of empirical and analytical tools to conduct parallel analyses of involuntary parttime work and unemployment in the U.S. labor market. In the empirical analysis, we document that the similar cyclical behavior of involuntary part-time work and unemployment masks major differences in the underlying dynamics. Unlike unemployment, variations in involuntary parttime work are mostly explained by its interaction with full-time employment, and since the Great Recession employed workers are at a greater risk of working part-time involuntarily than being unemployed. In the theoretical analysis, we show that the higher probability of regaining full-time employment is key to distinguish involuntary part-time work from unemployment from a worker's perspective. We also quantify the welfare costs of cyclical fluctuations in involuntary part-time work, and the amplification of these costs arising from the elevated levels of involuntary part-time work observed since the Great Recession.
\end{abstract}

Keywords: Employment; Involuntary part-time work; Welfare; Great Recession

JEL codes: E21; E32; J21.

${ }^{*}$ We are grateful to Mike Elsby, Marion Goussé, Gregor Jarosch, Grégory Jolivet, Guy Laroque, Jean-Marc Robin and Robert Shimer for helpful discussions, and Juan F Jimeno for his dicussion of an earlier version of the paper. We also thank seminar participants at the Cambridge SaM Conference, the University of Bristol, Sciences Po, University of Copenhagen, the Dale Mortensen Centre Conference on Labour Market Models and their Applications, and the joint ECB/CEPR labour market workshop on "Job creation after the crisis" for their comments and suggestions. All errors are our own.

${ }^{\dagger}$ Address: Sciences Po Department of Economics, 28 rue des Saints-Pères, 75007 Paris, France - Phone: $+33(0) 678$ 254938 - Email: danielbm@gmail.com

${ }_{\ddagger}^{\ddagger}$ Address: Department of Economics, University of Bristol, 8 Woodland Road, Bristol BS8 1TN, United Kingdom Phone: +44(0)117331 7912 - E-mail: etienne.lale@bristol.ac.uk 


\section{Introduction}

In this paper we argue that involuntary part-time work has been overlooked by research on the dynamics of labor markets, which has mainly focused on unemployment. The notion of involuntary part-time work is closely related to that of unemployment, in that both entail a constraint on workers' desired labor supply. An individual is considered to be working part-time involuntarily in U.S. statistics if she cannot find a full-time job or faces slack demand conditions in her job. In our view, there are at least two reasons to take this theme seriously. First, the magnitude and cyclical nature of the risk of working part-time involuntarily are comparable to those of unemployment. In fact, during the aftermath of the Great Recession, employed workers were at a greater risk of having to take up involuntary part-time work than of becoming unemployed. Second, from an individual's perspective, spells of involuntary part-time work seem to spawn a distinct labor market state compared with unemployment. For instance, a full-time worker who takes on a part-time job suffers a large reduction in earnings while remaining employed and is unlikely to receive an income compensation from publicly-provided insurance programs. ${ }^{1}$

The first contribution of the paper is to provide a detailed empirical analysis of involuntary parttime work in the U.S. labor market. We operationalize a Markov-chain representation of the labor market in the spirit of Borowczyk-Martins and Lalé (2014) (henceforth BML) to study the sources of fluctuations in the involuntary part-time employment rate. To emphasize differences with respect to unemployment, we conduct a parallel analysis of the unemployment rate. Using data from the Current Population Survey and measurement tools developed by Shimer (2012) and Elsby, Hobijn and Şahin (2015), we document a number of new facts.

First, the dynamics of involuntary part-time employment are fast (in particular faster than that of unemployment) and are chiefly driven by movements in inflows. Cast in terms of Darby, Haltiwanger and Plant (1986)'s classic contribution, the "ins" win over the "outs" by a substantial margin (a 62:38 split). This sharply contrasts with an ins-and-outs split for the unemployment rate of 46:54. ${ }^{2}$ Second, we find that separations from full-time work are the main source of fluctuations in the involuntary part-time employment rate, whereas unemployment outflows to non-participation and full-time jobs dominate the behavior of the unemployment rate. This highlights that involuntary part-time work is harmful in a different way than unemployment, which is mainly detrimental for long unemployment durations, when the outflow rate is low. Third, the vast majority of transitions between full-time employment and involuntary part-time work takes place at the same employer. This contrasts with unemployment which, except for temporary layoffs and recalls, redistributes workers across employers. ${ }^{3}$ Based on these facts, a tentative answer to the question in the title of this work is: involuntary part-time work is bad because it represents a source of income instability to full-time workers but, compared to unemployment, it offers an alternative channel to regain full-time employment.

We go beyond description in the second part of the paper and combine results from our empirical

\footnotetext{
${ }^{1}$ In the United States, the largest public program that could be directed towards these earnings losses is the earned income tax credit (EITC). We evaluate that at least $40 \%$ of involuntary part-time workers cannot qualify for EITC.

${ }^{2}$ The numbers for unemployment we obtain in our sample are in between those reported by Fujita and Ramey (2009) and Shimer (2012) over a longer time frame.

${ }^{3}$ Fujita and Moscarini (2013) report that a large fraction of separated workers are recalled by their previous employer. As discussed later in the Introduction, we view their findings as complementary to ours. Yet, the unemployment pool is mostly composed of job seekers who were not employed previously or do not expect do be recalled.
} 
analysis with a theoretical framework. The framework we develop embodies search efforts, savings and a borrowing limit to capture the risk of being unemployed, which is well understood and documented as to its effects on consumption smoothing. Alongside the risk of unemployment, in our framework full-time employment entails a risk of working part-time involuntarily and public insurance is provided only for the unemployment risk. ${ }^{4}$ We anchor this framework to standard preference parameters and to the dynamics and policies of the U.S. labor market, and use a structural equation to infer the parameters that determine job search outcomes.

First, we show that, from an individual's perspective, involuntary part-time work is less detrimental than unemployment because of the very high rate at which part-time workers are brought back into full-time employment. That is, given our estimates of job availability parameters, if these workers were unemployed it would take them a high search effort to generate the same probability of moving into full-time employment. We estimate this premium in access to full-time work to be worth $5 \%$ of consumption during the first quarter of part-time work. Second, we use the model to measure the implications of the cyclical risk of involuntary part-time work, and its increased incidence observed in the wake of the Great Recession. We evaluate that eliminating the cyclical component of involuntary part-time work would increase welfare by $1 / 4$ to $1 / 3$ of a percentage point of lifetime consumption. These welfare losses are larger when the outflow to full-time employment decreases, which makes part-time work become similar to unemployment.

In light of our findings, it is perhaps surprising how little work has been done on involuntary part-time employment. The existing literature is quite diffuse, almost exclusively empirical and uses data mostly on labor market stocks (see e.g. Valletta and Bengali, 2013; Valletta and van der List, 2015). ${ }^{5}$ A possible explanation is the very strong correlation between unemployment and involuntary part-time work, which could justify focusing on one variable only. Our research suggests, however, that involuntary part-time work is worthy of a separate analysis, both for positive and normative reasons. First, the empirical behavior of involuntary part-time employment highlights separations from full-time work as an important source of labor market fluctuations, and which is underestimated by focusing exclusively on the dynamics of unemployment. Second, our numerical experiments show that the welfare costs of these separations are nonnegligible, and call for a complete evaluation of the welfare effects of creating an appropriate insurance mechanism. At present, however, the effects of short-time compensation and of similar policy schemes remain understudied, especially in comparison to the existing literature on unemployment insurance benefits. ${ }^{6}$

\footnotetext{
${ }^{4}$ We use data on workers who do not qualify for EITC to inform the model. Moreover, the assumption seems reasonable for the U.S. labor market: a few states operate short-time compensation programs but the take-up rates for these benefits are typically low (Abraham and Houseman, 2014).

${ }^{5}$ To our knowledge, the main exceptions to this somewhat sweeping summary of the literature are the early papers by Stratton (1996) and Barrett and Doiron (2001), the article by Cajner et al. (2014) and Borowczyk-Martins and Lalé (2014). Stratton (1996) uses March CPS data to compare average one-year-apart transition probabilities from unemployment, non-participation and voluntary part-time employment. Barrett and Doiron (2001) compares wages among voluntary and involuntary part-time workers in Canada. Cajner et al. (2014) reports the contribution of various labor market states to yearly changes in involuntary part-time employment. Finally, we note that in the study of the part-time wage penalty by Hirsch (2005), some regressions include a variable for transitions to and from full-time work.

${ }^{6}$ In fact, after the early analyses of short-time compensation by Burdett and Wright (1989) and Hotchkiss and Wright (1988), we find no article on this theme until a recent period. The Great Recession prompted the adoption of such policy schemes in several OECD countries, which in turn helped raise attention on this topic. The focus of most papers is on the employment effects of short-time compensation, as in Hijzen and Venn (2011) and Cahuc and Carcillo (2011). Braun and Brügemann (2014) provide an in-depth theoretical analysis of the welfare effects of this policy instrument.
} 
Concomitant with the need to bridge this gap in the literature, understanding the evolution of involuntary part-time work after the Great Recession has become a priority for the Federal Reserve Board. In her 2014 address to the annual Jackson Hole Conference, Yellen (2014) lists involuntary part-time work among the top labor market "surprises" worth worrying about. In paralell, a number of recent research notes by FED economists analyze the evolution of involuntary part-time in light of the structural/cyclical distinction (see e.g. Cajner et al., 2014; Valletta and van der List, 2015). Importantly, with respect to this debate, we find that, in the aftermath of the Great Recession, flows from/to involuntary part-time employment to/from full-time employment are taking longer to recover compared to unemployment flows. This suggests that involuntary part-time is indeed a relevant measure of labor market slack, particularly for recoveries characterized by low job creation. ${ }^{7}$

In the broader area of labor market dynamics research, we think our investigation dovetails well with the facts recently uncovered by Fujita and Moscarini (2013). Their analysis of temporary layoffs and recalls describes an alternative protocol to end an employment relationship, and that affects the probability of a future rematch. Involuntary part-time work can be cast in similar terms. It involves, not strictly speaking a severance, but rather a temporary suspension of the employment relationship one highly likely to be resumed in the next state. Fujita and Moscarini (2013) and Fernández-Blanco (2013) further develop search-equilibrium models in which firms can re-hire former employees. They show that these models yield new insights into labor market dynamics compared with the canonical search-equilibrium model with no recall. The addition of an involuntary part-time employment state to such models is an exciting challenge, notably because the conventional search-equilibrium model assumes linear utility and thereby imposes restrictions on income and substitution effects. While recognizing the importance of these questions, we do not pursue them in this paper. Instead, we consider a framework with savings and a well-defined marginal rate of substitution between leisure and consumption, and use it to gauge the implications of exogenous changes in the rate of reallocation of full-time workers to part-time employment.

As a final consideration we relate our findings to existing evidence on involuntary part-time work in other labor markets. Perhaps even more accutely than in the U.S., empirical evidence on involuntary part-time work in an international context is quite limited. Notwithstanding, our own perfunctory assessment of international evidence indicates that the facts motivating our analysis of the U.S. labor market are also present in other countries. Using aggregate annual data from the OECD Labor Force Survey on 30 industrialized economies over the past twenty years, we first find that the involuntary part-time work is a pervasive phenomenon and that it affects a large number of workers in every country. The time-averaged involuntary part-time rate ranges between 1 and $8 \%$ of the labor force across the countries in our sample. Second, and most importantly, in the majority of the countries surveyed there is a very strong dynamic relationship between the unemployment rate and the involuntary part-time employment rate (contemporaneous correlation coefficients are positive and above 0.6 for 19 countries). This common experience of involuntary part-time work sharply contrasts with

\footnotetext{
${ }^{7}$ Interestingly, a recent paper by Blanchflower and Levin (2015) shows that unemployment is less relevant for assessing the amount of economic slack in a sluggish recovery because the employment gap is accounted for by involuntary part-time work and by workers who have dropped from the workforce but would rejoin it in good times. This echoes our finding about the changing composition of the pool of involuntary part-time work during the recession. Blanchwolfer and Levin also find that these dimensions of labor market slack have a downward impact on wages. Our model abstracts from such general equilibrium effects, but these would add to the negative welfare effects we tabulate.
} 
well-known cross-country differences in the extent and cyclicality of part-time employment. Taken together, these facts strongly suggest the existence of a common experience of involuntary part-time work in most advanced economies. In Appendix D.2 we present the main results of our analysis and provide details on the institutional context and measurement of part-time work across countries.

The paper is structured as follows. Section 2 offers a preliminary account of the concept, measurement and basic facts on involuntary part-time work. The bulk of our empirical analysis is presented in Section 3. Section 4 presents our quantitative framework and measures the welfare effects of involuntary part-time work. Section 5 concludes. There are two appendices to accompany the empirical analysis of the paper. A third appendix contains details and additional results to complement Section 4. Finally, some background information for the interested reader is included in a fourth appendix.

\section{Involuntary part-time work: Preliminaries}

The section introduces some preliminary facts about involuntary part-time work in the U.S. labor market. We refer the reader to Appendices A and B for details.

\subsection{Data and definition}

The Current Population Survey, administered by the Bureau of Labor Statistics (BLS), systematically records workers' reasons for working part-time. These measurements form the basis of our empirical investigation. Our main source of data are the monthly files of the CPS for the years 1994-2015. Although the CPS came into existence long before January 1994, part-time workers can only be reliably identified from this period onwards (see BML for details).

The definition of a part-time job we use in this paper is identical to that used in BML. A part-time job involves (strictly) less than 35 total usual hours of work per week. The metric of hours worked (usual hours) is in our view more adequate than actual hours. Total usual hours include both usual paid and unpaid overtime hours. The 35 hour cutoff is the same as the one used by the BLS to define part-time work (http: //www.bls.gov/bls/glossary.htm).

As for involuntary part-time work, our definition is also standard and based on the following question of the CPS questionnaire (see U.S. Bureau of the Census, 2013):

Some people work part time because they cannot find full time work or because business is poor. Others work part time because of family obligations or other personal reasons. What is (name's/your) MAIN reason for working part time?

Implicit in the question above are two broad categories of part-time workers: those who perform part-time work because of constraints originating from the demand side of the labor market, and those who work part-time for reasons related to labor supply. Involuntary part-time work refers to the first category, although it should be recognized that some workers from the second group may also be working part-time involuntarily. ${ }^{8}$ Within the first category, we can further distinguish those

\footnotetext{
${ }^{8}$ One such example is those who are constrained to work part-time because they cannot arrange childcare. A possible motivation for the conventional definition of involuntary part-time work is that it isolates those components of involuntary employment that are directly related to the business cycle.
} 
working part-time due to slack demand conditions from those who report that they cannot find a full-time job. The distinction is relevant in that the former cause reflects job instability in full-time employment, whereas the latter relates to the behavior of job seekers and the constraints that they face. Finally, a word of caution is in order. Like many other items collected in labor force surveys, these measurements are, to a certain extent, subjective. We discuss this issue in greater depth in Appendix B.4.

\subsection{Who is working part-time involuntarily and why?}

To answer the question above we give a brief description of the population characteristics of involuntary part-time workers during the sample period. To get some perspective, it is useful to compare them to voluntary part-time and unemployed workers. Columns 1 to 3 of Table 1 show how the stocks of involuntary part-timers, voluntary part-timers and unemployed are distributed across different categories of observed dimensions of worker heterogeneity (gender, age, education and marital status). We notice that the composition of the stock of involuntary part-time employment is very similar to that of the unemployment stock across any of the heterogeneity dimensions considered, and strikingly dissimilar to the stock of voluntary part-time workers. For the latter observation, a telling comparison concerns gender composition, well-known to be strongly skewed towards women in part-time, yet much closer to parity for involuntary part-time employment (resp. 29.8/70.2 vs. 44.7/55.3). The same pattern is present in comparisons based on the distribution of age, education and marital status. In short, unemployed and involuntary part-time workers are more likely to be in their prime age (25 to 54 years of age), from lower education levels and not married. These patterns suggest that, unlike voluntary part-timers, these are typically individuals with a strong labor force attachment and/or lower than average employment opportunities. The fact that the average unemployed worker is statistically almost the same as the average involuntary part-timer underscores the suitability of the inclusion of these individuals in a broader measure of unemployment, such as the U-6 measure of the BLS. ${ }^{9}$

In columns 4 to 6 of Table 1, we report involuntary part-time rates for the whole labor force and for different categories of workers. Starting with column 6, we note that the vast majority of parttime workers choose it for noneconomic reasons: the involuntary part-time rate is $2.72 \%$ (top row of column 6) while the overall (not reported) part-time rate is $16.6 \%$. The remaining cells of column 6 quantify the incidence of this risk across different worker categories. Some telling patterns stand out. First, women are subject to a near full percentage-point greater underemployment risk compared to men. Second, the risk of involuntary part-time work decreases with age and with the level of education. For instance, compared to prime-age and older workers, the young experience involuntary part-time rates that are roughly two times greater. Finally, single or previously married individuals are more likely to be underemployed compared to those who are married.

Columns 4 and 5 disaggregates involuntary part-time work between the two recorded reasons (i.e. whether the individual is working part-time due to slack economic conditions or because she cannot find a full-time job). The incidence of involuntary part-time at the aggregate is roughly evenly

\footnotetext{
${ }^{9}$ The BLS publishes several measures of labor underutilization (see http://www.bls.gov/lau/stalt.htm). The measure called U-6 includes the number of involuntary part-time workers alongside the unemployed and workers who are marginally attached to the workforce; see e.g. Sum and Khatiwada (2010). The BLS often use the acronym PTER (part-time for economic reason) to refer to involuntary part-time workers.
} 
Table 1. Cross-sectional characteristics of involuntary part-time work

\begin{tabular}{|c|c|c|c|c|c|c|}
\hline & \multicolumn{3}{|c|}{ Composition of the pool of: } & \multicolumn{3}{|c|}{ Involuntary part-time rate: } \\
\hline & $\begin{array}{l}\text { involuntary } \\
\text { part-timers } \\
\text { (1) }\end{array}$ & $\begin{array}{l}\text { voluntary } \\
\text { part-timers } \\
\text { (2) }\end{array}$ & $\begin{array}{c}\text { unemployed } \\
\text { workers } \\
\text { (3) }\end{array}$ & $\begin{array}{c}\text { Slack work } \\
\text { (4) }\end{array}$ & $\begin{array}{l}\text { Unable to find } \\
\text { full-time work } \\
\text { (5) }\end{array}$ & $\begin{array}{l}\text { Sum } \\
(6)\end{array}$ \\
\hline Total & 100.0 & 100.0 & 100.0 & 1.54 & 1.18 & 2.72 \\
\hline \multicolumn{7}{|l|}{ (a) Gender } \\
\hline Men & 44.7 & 29.8 & 55.9 & 1.42 & 0.89 & 2.30 \\
\hline Women & 55.3 & 70.2 & 43.5 & 1.67 & 1.53 & 3.20 \\
\hline \multicolumn{7}{|l|}{ (b) Age } \\
\hline 16 to 24 years & 29.7 & 36.9 & 33.0 & 2.34 & 2.80 & 5.16 \\
\hline 25 to 54 years & 60.9 & 49.6 & 58.3 & 1.42 & 0.93 & 2.34 \\
\hline 55 to 64 years & 9.4 & 13.5 & 8.3 & 1.26 & 0.73 & 1.98 \\
\hline \multicolumn{7}{|l|}{ (c) Education } \\
\hline Less than high-school & 21.5 & 18.2 & 24.8 & 3.02 & 1.82 & 4.85 \\
\hline High-school graduates & 37.7 & 24.3 & 35.3 & 1.92 & 1.52 & 3.44 \\
\hline Some college & 22.7 & 31.7 & 21.6 & 1.43 & 1.18 & 2.61 \\
\hline College or higher education & 14.5 & 21.8 & 13.5 & 0.74 & 0.64 & 1.37 \\
\hline (d) Marital status & & & & & & \\
\hline Married & 36.4 & 46.3 & 34.8 & 1.12 & 0.65 & 1.78 \\
\hline Widowed; divorced; separated & 16.7 & 9.3 & 15.1 & 1.87 & 1.32 & 3.18 \\
\hline Single & 47.0 & 44.4 & 49.2 & 2.14 & 2.12 & 4.26 \\
\hline
\end{tabular}

NOTE: CPS data, averages over the period 1994m01-2015m11. All entries in the table are reported in percent.

distributed among the two reasons ("slack work" is slightly more important). When we look at this distribution for specific worker categories, "slack work" remains the dominant reason (the only exception being young workers), but now the differences can be far more substantial. This is the case for women, prime-age and older workers and individuals with less than a high-school education. As we document in Subsection 3.2, while the risk of part-time work due to slack demand conditions is distributed unevenly across workers, it nevertheless affects all segments of the labor force at business cycle frequencies, particularly so during and after the Great Recession.

\subsection{Cyclical behavior}

The key observations motivating our analysis are the countercyclical behavior of the involuntary parttime employment rate during the postwar history of the U.S. labor market, and especially its spectacular response during the Great Recession and its aftermath. As mentioned previously, data restrictions imply that the analysis based on worker flows can only cover a narrow time period. However, using only stock data it is possible to track the aggregate time-series evolution of part-time work over a longer time period. Combining data from the BLS and the March CPS, we construct time series of the involuntary part-time employment rate and the part-time employment share since $1955 .{ }^{10}$ Figure 1 displays the long-run time series of the involuntary part-time employment rate, alongside the

\footnotetext{
${ }^{10}$ See Appendix A for details. In the appendix, we compare the unadjusted BLS series of overall part-time and involuntary part-time workers with their adjusted counterparts. We show that the BLS series lead, respectively, to underand over-estimating the actual numbers. Also, the fact that we are able to reduce the discrepancy around the 1994 break in the time-series does not mean that we could have extended our analysis of labor market flows to the pre-1994 period. We can correct aggregate labor market stocks, but there is little we can do about individual transitions in two consecutive periods, which are required to compute labor market flows.
} 


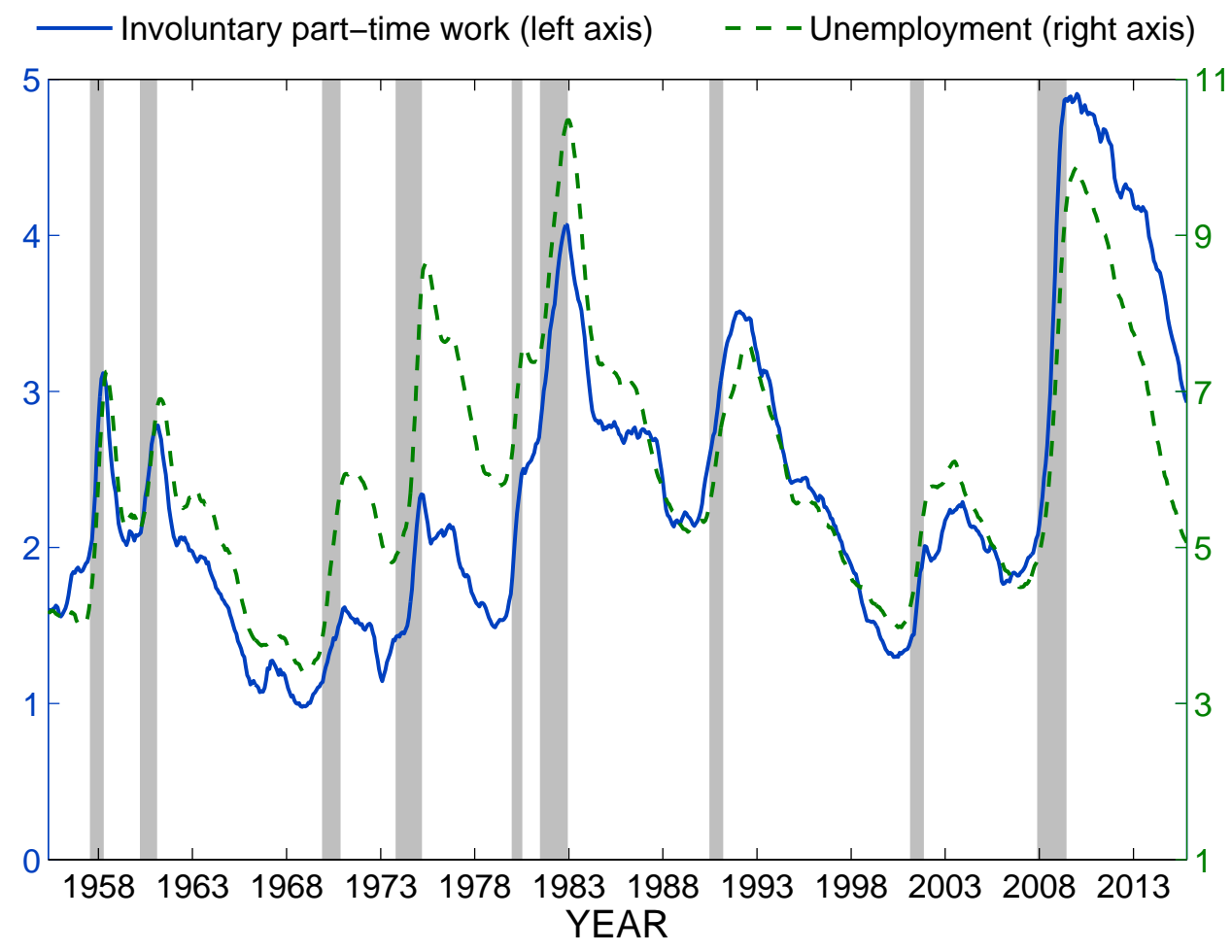

Figure 1. Involuntary part-time work and the unemployment rate: May 1955 - November 2015 MA-smoothed, seasonally-adjusted time-series. Gray-shaded areas indicate NBER recession periods. See Appendix A.1 for details about the construction of the time-series of involuntary part-time work.

unemployment rate. The two facts we alluded to above are indeed very salient.

To interpret the pronounced countercyclicality of the involuntary part-time employment rate, it is useful to consider the following decomposition:

$$
\underbrace{\frac{\text { Involuntary }}{\text { Labor force }}}_{\begin{array}{c}
\text { Involuntary part-time } \\
\text { employment rate }
\end{array}}=\underbrace{\frac{\text { Involuntary }}{\text { Part-time }}}_{\begin{array}{c}
\text { Incidence of involuntary } \\
\text { work in part-time jobs }
\end{array}} \times \underbrace{\frac{\text { Part-time }}{\text { Employed }}}_{\begin{array}{c}
\text { Part-time } \\
\text { employment share }
\end{array}} \times \underbrace{\frac{\text { Employed }}{\text { Labor force }}}_{\begin{array}{c}
\text { One minus the } \\
\text { unemployment rate }
\end{array}} .
$$

It highlights that the cyclical behavior of the involuntary part-time employment rate can take place in a number of different ways. In particular, the last term on the right-hand side indicates that, contrary to what we see in Figure 1, the involuntary part-time employment and unemployment rates could even be negatively correlated. In fact, what we find is that the countercyclicality of the left-hand side variable is the result of the prominent countercyclicality of the part-time employment share (a fact documented in BML), and more importantly, the increased incidence of involuntary part-time work during recessions.

To establish these facts, we undertake a variance decomposition of the involuntary part-time rate based on the equation above. The outcome are estimated shares of the variation of the left-hand side variable attributable to fluctuations in each of the three right-hand side variables. Table 2 reports the results of this exercise for three alternative series: the long-run time series starting in January 1968 onwards (Series 1), the same time series but for a narrow window starting after the 1994 CPS redesign (Series 2), and finally, the time series computed directly from the monthly CPS for workers 
aged between 16 to $64 .{ }^{11} 12$ During all three periods the bulk of the variation in the involuntary part-time rate results from changes in the incidence of involuntary part-time work (89\%). If anything, changes in the unemployment rate dampen the variation in the involuntary part-time employment rate, albeit by a small amount (less than $8 \%$ ).

Table 2. Involuntary part-time employment rate: Variance decomposition

\begin{tabular}{lccc}
\hline Variance contribution of: & $\frac{\text { Involuntary }}{\text { Part-time }}$ & $\frac{\text { Part-time }}{\text { Employed }}$ & $\frac{\text { Employed }}{\text { Laborforce }}$ \\
\hline January 1968 - November 2015, Series 1 & 88.5 & 18.9 & -7.5 \\
January 1994 - November 2015, Series 2 & 88.6 & 18.6 & -7.2 \\
January 1994 - November 2015, Series 3 & 89.2 & 16.7 & -5.9 \\
\hline
\end{tabular}

\begin{abstract}
NotE: Series 1: BLS time-series for workers aged 16 and above, adjusted for under- and overestimates before 1994 (see Appendix A.1). Series 2: BLS time-series for workers aged 16 and above; the period is from 1994 onwards and therefore the time-series are unadjusted. Series 3: Own time-series computed from the monthly file of the CPS for workers aged 16 to 64 . The monthly time series are transformed to quarterly and taken in log as deviation from a HP trend with smoothing parameter $10^{5}$. Variance contributions are reported in percent.
\end{abstract}

\title{
3 Fluctuations in involuntary part-time work
}

Having characterized involuntary part-time work in the cross section and over the business cycle, we now analyze in detail the sources of its cyclical behavior. Critical for our story is the idea that, though similarly countercyclical, involuntary part-time employment and unemployment are distinct labor market states, exhibiting different dynamics and interactions with other labor market states. In this section, we establish this result first by using data for the whole sample period, and then by focusing the discussion on the Great Recession and its aftermath.

\subsection{The ins and outs of involuntary part-time work}

To begin this subsection, we review the empirical framework that underlies our measurements. We then describe the dynamics of involuntary part-time work and, for comparative purposes, we conduct a parallel analysis for unemployment. ${ }^{13}$

\subsubsection{Empirical framework}

Our description of the labor market classifies workers in five labor market states: full-time work $(F)$, part-time work, voluntary $(V)$ or not $(I)$, unemployment $(U)$ and non-participation $(N)$. Formally,

\footnotetext{
${ }^{11}$ Because the series of the number of part-time workers is only available since 1968, we cannot go back until 1955 .

${ }^{12}$ Series 1 and 2 are based on the published time series of the BLS, which are computed for workers aged 16 and above and with no upper restriction on age.

${ }^{13}$ Although the dynamics of unemployment are well documented (see e.g. Fujita and Ramey 2009; Shimer 2012), we find it useful to describe them alongside those of involuntary part-time work. The fact that, due to data restrictions, we focus on a shorter observation window than the one that is typically used in studies of unemployment fluctuations in the U.S. (usually starting in the late 1960s) makes this exercise informative.
} 
labor market stocks in period $t$ are stacked in vector

$$
\boldsymbol{s}_{t}=\left[\begin{array}{lllll}
F & V & I & U & N
\end{array}\right]_{t}^{\prime}
$$

Following much of the literature on labor market flows, we characterize the dynamics of $\boldsymbol{s}_{t}$ by means of a first-order discrete-time Markov chain model. We assume that the evolution of labor market stocks is governed by: $\boldsymbol{s}_{t}=\boldsymbol{M}_{t} \boldsymbol{s}_{t-1}$, where $\boldsymbol{M}_{t}$ is a matrix the elements of which are transition probabilities $p(i \rightarrow j)$ between labor market states $i$ and $j$. These probabilities satisfy $\sum_{j} p(i \rightarrow j)=1$ for any $i$ and are the main ingredient of our empirical analysis.

To obtain estimates of transition probabilities, we match individual respondents in the CPS. Those observations are used to produce time series of labor stocks and gross flows which we then adjust to account for a number of potential biases and measurement issues. Details on how we address specific measurement problems are provided in Appendix A. All reported results in the following sections are based on the adjusted series.

\subsubsection{Inflows, outflows and their cyclical behavior}

The first dimension along which we want to characterize the dynamics of involuntary part-time work is that of its interaction with other labor market states. Table 3 reports sample averages of inflow and outflow transition probabilities of involuntary part-time work (left panel) and unemployment (right panel). ${ }^{14}$ A first striking result is displayed in the bottom row of both panels of Table 3 , which displays the sum of various inflow and outflow transition probabilities to involuntary part-time work and unemployment (resp. left- and right-hand side panels). The involuntary part-time employment rate exhibits spectacularly fast dynamics, with almost three quarters of the stock entering in the previous month (69.1\%) and a similarly large share leaving in the following one $(61.4 \%)$. Over the same period, these numbers are 41.0 and $39.1 \%$ for unemployment inflows and outflows. This is quite extraordinary given how unusually fast the dynamics of unemployment in the U.S. are in an international context. What is more, even when we remove movements between involuntary and voluntary part-time employment from this accounting exercise, the dynamics of involuntary part-time are still higher compared to those of unemployment (44.4 vs $39.1 \%$ ).

Focusing on involuntary part-time first, we see that full-time employment is the most relevant state of origin and destination. On average, $31.1 \%$ of all involuntary part-timers was employed fulltime in the previous month, and a slightly lower fraction $(30.3 \%)$ will enter a full-time job next month. Perhaps surprisingly, movements between involuntary and voluntary part-time employment are also large (the average transition probabilities are 18.4 and $17 \%$ resp. for inflows and outflows). ${ }^{15}$ Finally, transitions between involuntary part-time and unemployment are smaller, and those with non-participation very small. Moving on to unemployed workers, we see that, like involuntary parttimers, they are more likely to have been or become full-time employed respectively in the previous and following month (16.4\% and 14.4\%). Different to involuntary part-time, transitions between

\footnotetext{
${ }^{14}$ The inflow transition from state $i$ to $j$ at time $t$, denoted $q(i \rightarrow j)$, is the ratio of the gross flow from state $i$ to $j$ over the stock of workers in state $j$. That is, $q(i \rightarrow j)=\#\{i \rightarrow j\} / \#\{j\}$ (with $\#\{$.$\} indicating cardinality, and the numerator and$ denominator are measured at time $t$ ). The outflow transition probabilities are the elements of the transition matrix $\boldsymbol{M}_{t}$.

${ }^{15}$ This is despite the fact that we address potential measurement error in transitions between involuntary and voluntary part-time work, and discard a significant fraction of the transitions observed in the raw data; see Appendix A.2.
} 
Table 3. Transition probabilities: Sample averages

\begin{tabular}{|c|c|c|c|c|c|c|c|}
\hline \multicolumn{4}{|c|}{ Involuntary part-time work } & \multicolumn{4}{|c|}{ Unemployment } \\
\hline \multicolumn{2}{|l|}{ Inflows } & \multicolumn{2}{|c|}{ Outflows } & \multicolumn{2}{|l|}{ Inflows } & \multicolumn{2}{|l|}{ Outflows } \\
\hline$q(F \rightarrow I)$ & 31.1 & $p(I \rightarrow F)$ & 30.3 & $q(F \rightarrow U)$ & 16.4 & $p(U \rightarrow F)$ & 14.4 \\
\hline$q(V \rightarrow I)$ & 18.4 & $p(I \rightarrow V)$ & 17.0 & $q(V \rightarrow U)$ & 6.38 & $p(U \rightarrow V)$ & 7.61 \\
\hline$q(U \rightarrow I)$ & 14.5 & $p(I \rightarrow U)$ & 10.2 & $q(I \rightarrow U)$ & 4.09 & $p(U \rightarrow I)$ & 5.74 \\
\hline$q(N \rightarrow I)$ & 5.05 & $p(I \rightarrow N)$ & 3.79 & $q(N \rightarrow U)$ & 14.2 & $p(U \rightarrow N)$ & 11.4 \\
\hline$\sum_{i \neq I} q(i \rightarrow I)$ & 69.1 & $\sum_{j \neq I} p(I \rightarrow j)$ & 61.4 & $\sum_{i \neq U} q(i \rightarrow U)$ & 41.0 & $\sum_{j \neq U} p(U \rightarrow j)$ & 39.1 \\
\hline
\end{tabular}

NOTE: CPS data, averages over the period 1994m01-2015m11. All entries are reported in percent.

unemployment and non-participation are high (just short of the triple of the corresponding figures of the left-hand side panel).

Figure 2 complements this static portrait by displaying the evolution of the most relevant outflow transition probabilities in Table 3 over the sample period. In each plot the same transition is shown both for involuntary part-time (solid line) and unemployment (dashed line). We first comment on the dynamic behavior of inflow transitions from full-time employment. It is well-known that the inflow probability to unemployment spikes in recessions and returns to its pre-crisis level quickly, while the outflow rate from unemployment falls and recovers slowly. Both patterns are present in Figure 2a. The evolution of the inflow probability to involuntary part-time employment on impact is similarly characterized by a jump upwards. However, its recovery is much slower, and possibly even non-existent (after the 2001 recession, $p(F \rightarrow I)$ never returned to its pre-crisis level). The evolution of the two probabilities is also quantitatively different during the Great Recession. The increase in $p(F \rightarrow I)$ is far greater (so much so that the two lines intersect at the end of the recessionary period), and throughout the whole post-recession period (which extends over a six year period) it remains at historically high levels.

Turning to the evolution of outflow probabilities from these two states to full-time employment, Figure $2 \mathrm{~b}$ shows that $p(I \rightarrow F)$ and $p(U \rightarrow F)$ follow a similar trajectory to the aggregate job finding rate. Both probabilities rise steadily in normal times and fall slowly starting just before, or at the very beginning of recession, and extending over a period that goes beyond the end of the recession. It is noticeable that the solid line exhibits lower variation in both upturns and downturns. In the aftermath of the Great Recession, unemployment outflows towards full-time employment have not yet fully recovered (hence the term jobless recovery) but are close to their pre-crisis level. In contrast, outflows from involuntary part-time only seem to start increasing in 2014, leaving them well below their precrisis level. These responses underscore the magnitude and persistence of the shock and the ongoing slack in the labor market.

The two figures in the middle panel of Figure 2 plot transition probabilities between the two labor market states of interest $(I$ and $U$ ) and voluntary part-time employment $(V)$. Like full-time jobs, voluntary part-time jobs become scarcer in recessions, leading to a decrease in the voluntary part-time 


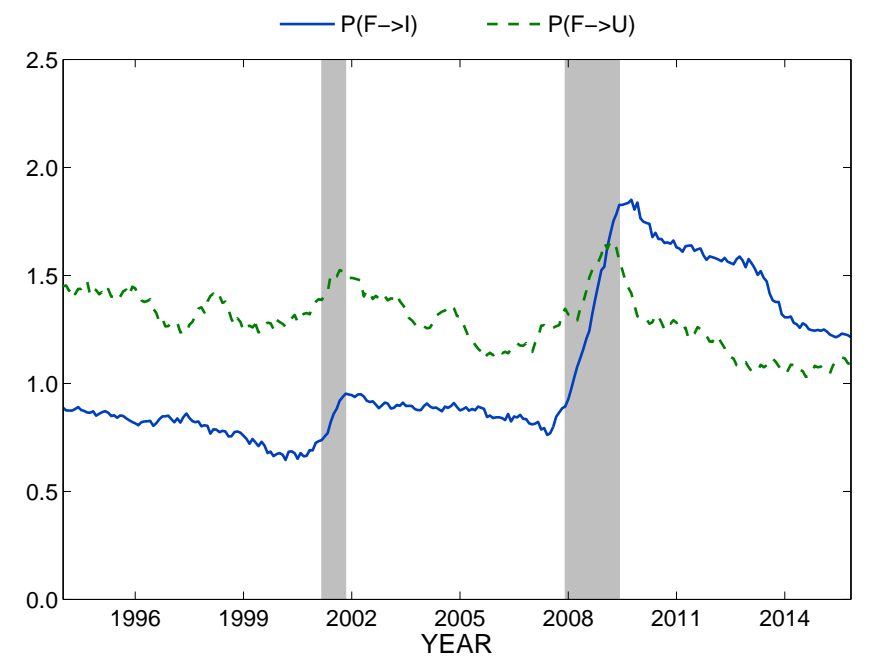

(a) Inflows from full-time employment

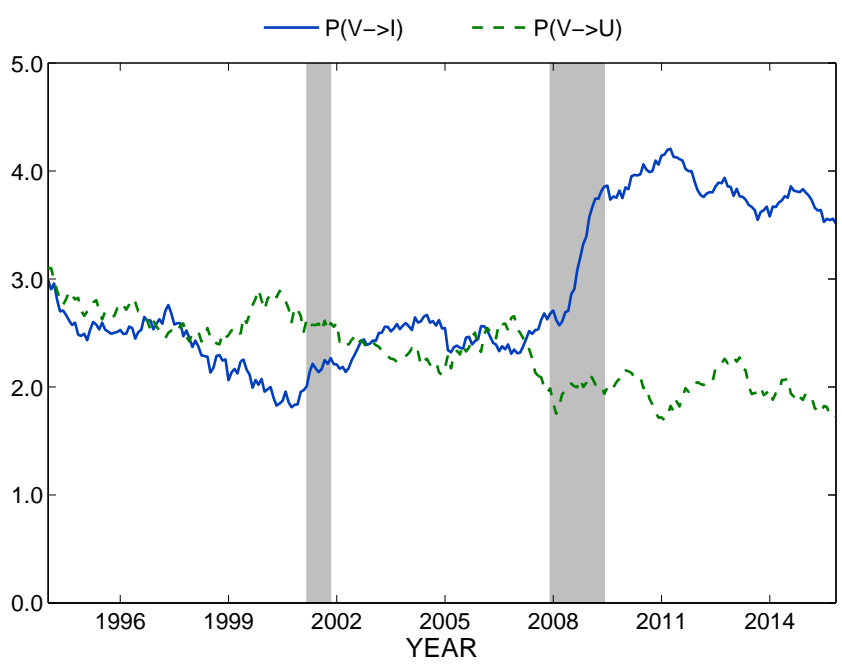

(c) Inflows from voluntary part-time employment

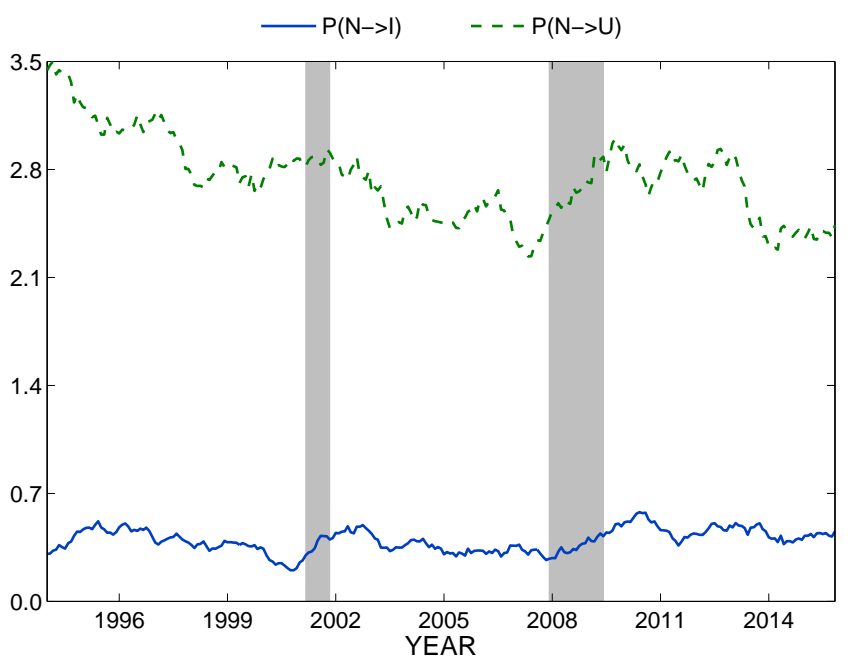

(e) Inflows from non-participation

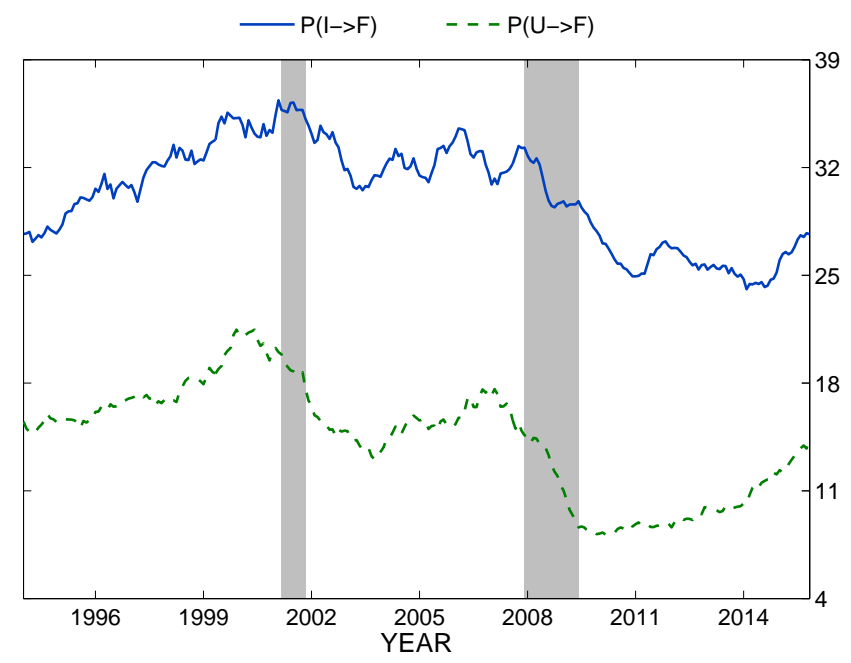

(b) Outflows to full-time employment

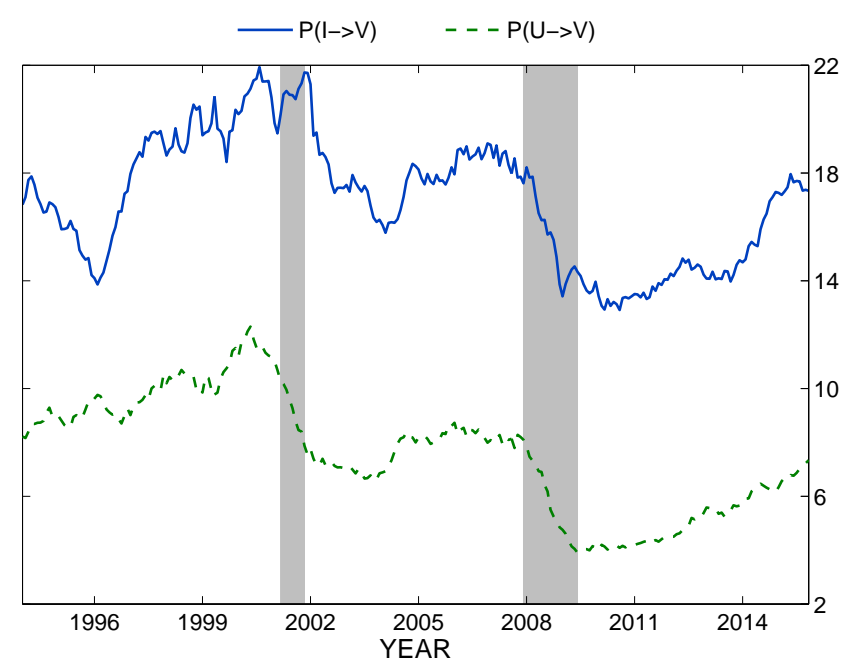

(d) Outflows to voluntary part-time employment

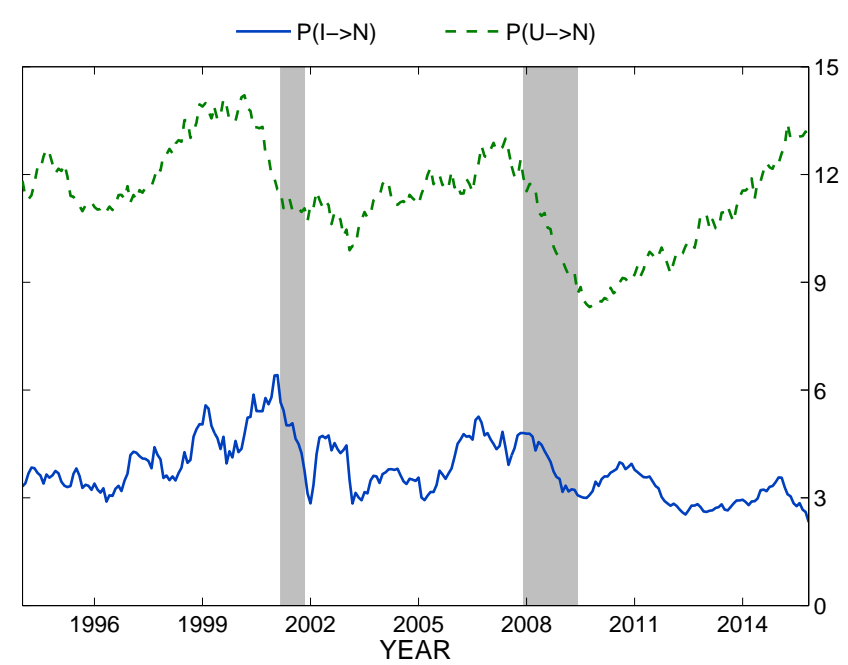

(f) Outflows to non-participation

Figure 2. Transition probabilities: Comparing involuntary part-time work and unemployment MA-smoothed, adjusted series (see Appendix A.2 for details about the adjustments). Gray-shaded areas indicate NBER recession periods. 
rate. However, there are some notable differences between the cyclical dynamics of the associated flow rates. While $p(V \rightarrow U)$ is surprisingly acyclical and exhibits a downward trend, the behavior of $p(V \rightarrow I)$ on impact is just like the one displayed by other employment outflow rates (jumping at the onset of the recession), and is even more persistent than that of $p(F \rightarrow I)$. It remains close to its recessionary peak six years later. As can be seen by comparing Figures $2 d$ and $2 b$, the outflows to voluntary part-time behave no differently from their counterparts to full-time employment. However, it is apparent that $p(I \rightarrow V)$ recovered faster compared to $p(U \rightarrow V)$, whereas the opposite was true in outflow rates to full-time employment.

Finally, Figures $2 \mathrm{e}$ and $2 \mathrm{f}$ track the evolution of flow rates to non-participation. Consistent with the picture provided by a comparison of sample means, and in spite of similar co-movement with the cycle, the cyclicality of non-participation flows is more pronounced with unemployment. In fact, there is almost no interaction between involuntary part-time work and non-participation, which dovetails with the idea that non-participants would not take any job if they were to work. We will confirm below that, on the other hand, non-participation plays a prominent role in determining unemployment fluctuations - confirming the importance of the participation margin for unemployment fluctuations, in the words of Elsby, Hobijn and Şahin (2015).

\section{Variance decomposition}

A convenient way to assess the importance of fluctuations in the different transition probabilities is to decompose the variation of the involuntary part-time employment rate into their individual contributions. These parameters, often referred to in the literature as beta coefficients, are defined as follows:

$$
\beta_{i v}^{i j}=\frac{\operatorname{Cov}\left(\Delta i v_{t}, \Delta i \tilde{v}_{t}^{i j}\right)}{\operatorname{Var}\left(\Delta i v_{t}\right)}
$$

$\Delta \tilde{v}_{t}^{i j}$ denotes changes in the counterfactual involuntary part-time employment rate whose evolution is only based on the past and contemporaneous changes in a particular transition probability $p(i \rightarrow j)$. It can be shown that the variation in the $i v_{t}$ is approximated by the sum of variance contributions of each flow hazard. That is:

$$
\sum_{i \neq j} \beta_{l}^{i j} \approx 1
$$

In practice, we estimate these parameters by regressing each series of counterfactual changes $\tilde{i v}_{t}{ }^{i j}$ on the observed changes in the involuntary part-time employment rate. Our numbers are reported in Table 4. By and large, the estimated beta coefficients confirm the picture we have been constructing thus far. For both rates, the ins and outs of full-time employment are quantitatively very important, but much more so for involuntary part-time vis-a-vis unemployment (60.5 vs $36.4 \%$ ). In line with our comments of Figure 2a, the inflow from full-time employment plays a prominent role in the cyclicality of the involuntary part-time employment rate $(35.5 \%)$. If we add to that the contribution of $p(V \rightarrow I)$, transitions from employment states explain $50.4 \%$ of the variation in $i v_{t}$. To our great 
Table 4. Variance contributions: Comparing involuntary part-time work and unemployment

\begin{tabular}{|c|c|c|c|c|c|c|c|}
\hline \multicolumn{4}{|c|}{ Involuntary part-time work } & \multicolumn{4}{|c|}{ Unemployment } \\
\hline \multicolumn{2}{|l|}{ Inflows } & \multicolumn{2}{|c|}{ Outflows } & \multicolumn{2}{|l|}{ Inflows } & \multicolumn{2}{|l|}{ Outflows } \\
\hline$\beta(F \rightarrow I)$ & 35.5 & $\beta(I \rightarrow F)$ & 25.0 & $\beta(F \rightarrow U)$ & 16.9 & $\beta(U \rightarrow F)$ & 19.5 \\
\hline$\beta(V \rightarrow I)$ & 14.9 & $\beta(I \rightarrow V)$ & 2.17 & $\beta(V \rightarrow U)$ & 4.38 & $\beta(U \rightarrow V)$ & 4.68 \\
\hline$\beta(U \rightarrow I)$ & 1.62 & $\beta(I \rightarrow U)$ & 9.42 & $\beta(I \rightarrow U)$ & 8.04 & $\beta(U \rightarrow I)$ & 9.90 \\
\hline$\beta(N \rightarrow I)$ & 9.66 & $\beta(I \rightarrow N)$ & 0.58 & $\beta(N \rightarrow U)$ & 19.0 & $\beta(U \rightarrow N)$ & 19.1 \\
\hline$\sum_{i \neq I} \beta(i \rightarrow I)$ & 61.6 & $\sum_{j \neq I} \beta(I \rightarrow j)$ & 37.2 & $\sum_{i \neq U} \beta(i \rightarrow U)$ & 48.3 & $\sum_{j \neq U} \beta(U \rightarrow j)$ & 53.2 \\
\hline$\sum_{i \neq I} \beta(i-$ & $+\sum$ & $\beta(I \rightarrow j)=9$ & & $\sum_{i \neq U} \beta(i-$ & + & $\beta(U \rightarrow j)=1$ & \\
\hline
\end{tabular}

NOTE: CPS data for the period 1994m01-2015m11. All entries are reported in percent.

surprise, the main driver of unemployment fluctuations during this period are fluctuations in and out of non-participation (38.1\%), followed closely by full-time employment (36.4\%). Finally, we assess the relative importance of the 'ins' and 'outs' for the evolution of both rates. Interestingly, the outs dominate the variation in the unemployment rate (48:53), whereas a similar breakdown of the variation of the involuntary part-time employment rate yields a 62:37 split.

To conclude our description of involuntary part-time work, we look at the importance of jobto-job reallocation in explaining movements between full-time and part-time work. Table 5 reports statistics on job-to-job transition probabilities before and after the Great Recession. By and large, we confirm the patterns documented more broadly in BML: these movements occur primarily within the same employer. The probability of moving to a different employer conditional on switching between full-time and involuntary part-time work and vice versa is between 11 to 13 percent in normal times, and between 5 and 7 after the Great Recession. As a result, the overall outflow probability from involuntary part-time to full-time work is mostly a within-firm phenomenon: that is, the overall outflow is $30.3 \%$ (cf. Table 2) and the outflow at the current employer is $28.1 \%$ (cf. Table 5). During the Great Recession this pattern is only reinforced: the surge in reallocation from full-time to involuntary part-time work (cf 2a) observed during this period is also a within-firm phenomenon.

Table 5. Transitions between full-time and part-time work and job-to-job transitions

\begin{tabular}{cccccc} 
& \multicolumn{2}{c}{ Before the Great Recession } & & \multicolumn{2}{c}{ After the Great Recession } \\
\cline { 2 - 3 } $\begin{array}{c}\text { Conditional job-to-job } \\
\text { transition probability }\end{array}$ & $\begin{array}{c}\text { Outflow at the same } \\
\text { employer }\end{array}$ & & $\begin{array}{c}\text { Conditional job-to-job } \\
\text { transition probability }\end{array}$ & $\begin{array}{c}\text { Outflow at the same } \\
\text { employer }\end{array}$ \\
\hline$F \rightarrow I$ & 10.36 & 0.74 & & 5.26 & 1.50 \\
$I \rightarrow F$ & 12.84 & 28.09 & & 6.94 & 24.18 \\
\hline
\end{tabular}

NotE: CPS data. Figures before the Great Recession are averages over the period 1994m01-2007m11. Figures after the Great Recession are averages over the period 2009m07-2015m11. All entries in the table are reported in percent. 
Based on the descriptive analysis we have made so far, we can already offer a more substantive characterization of involuntary part-time employment. First, involuntary part-time is a remarkably transitory labor market state. This seems to be the result of its dual nature. On the one hand, involuntary part-time is a state of employment. Compared to non-employed workers, involuntary part-timers are much more likely to return to a voluntary form of employment in the next period. Since the pool of unemployed and involuntary part-time workers is similarly composed of workers with strong labor force attachment (male, in prime age, with low educational attainment and unmarried), this difference likely reflects labor demand factors. Workers whose working hours (and possibly other contractual terms like wages and benefits) have been temporarily changed due to slack work seem to face better prospects to return to a desired employment relationship, compared to workers whose employment relationship has been fully severed (separations) or temporarily suspended with uncertain return (layoffs). The fact that transitions between involuntary part-time and full-time work occur mostly within the firm suggests that workers are quickly put away and brought back into full-time employment while staying at the same employer. On the other hand, involuntary part-time work involves a more fragile employment relationship vis-a-vis those held by voluntary part-time and full-time workers. Not only are workers in such situation more likely to quit (if given the chance), but also they are more likely to be forced out of the job into unemployment (when and if demand conditions further deteriorate).

The features of the involuntary part-time risk that we document add a fresh perspective on cyclical labor market dynamics, and which dovetails well with recent work in this field of research. According to this view, during an economic downturn workers face different reallocation risks, with distinct implications on their instantaneous welfare (work effort, pecuniary returns), search behavior and future labor market trajectories. On one extreme, employment relationships may be fully severed (separations), and workers either displaced to unemployment or non-participation. In the middle of this risk spectrum, employment relationships can be suspended with no certain recall or with recall date (temporary layoffs). The workings of this reallocation channel are documented in Fujita and Moscarini (2013). The authors show that workers on temporary layoff typically maintain a link with their previous employer and are therefore likely to regain employment in their previous firm. Finally, at the opposite extreme, the conditions of the employment relationship may be temporarily adjusted (namely reductions in wages and working hours), which the worker accepts for lack of a better option.

\subsection{The dynamics of involuntary part-time during the Great Recession}

The facts documented so far reveal a very pronounced cyclical response of specific inflows and outflows into involuntary part-time employment during the Great Recession, as well as the persistence of those responses in the ensuing five and half years. In this subsection, we use a different set of analytical tools to obtain a tangible understanding of involuntary part-time work during this period. In particular, based on the cross-sectional patterns uncovered in Subsection 2.2, we assess the explanatory power of two composition-effects hypotheses (similar methods are used in BML).

In Table 1, we highlighted that involuntary part-time employment is widespread but not uniformly distributed across different labor market segments. Thus, one could argue that the increase in the involuntary part-time employment rate came about through a recessionary shift of employment towards segments of the labor market that are more exposed to involuntary part-time risk. To assess 
this hypothesis, we decompose changes in the observed involuntary part-time rate in the contributions of observed changes in segment-specific involuntary part-time rates, and changes in the employment shares accounted for by different categories (gender, age, education and marital status). Table B2 in the Appendix displays the results of this exercise. The striking conclusion is that composition effects explain almost none of the recessionary increase in the involuntary part-time employment rate. Thus, understanding the increase in involuntary part-time work implies understanding the increases in group-specific probabilities of working part-time involuntarily. Notice that these results are in line with those found in BML regarding the countercyclical increase in the part-time employment share in private-firm salaried jobs during the Great Recession.

The second hypothesis we examine concerns changes in the composition of involuntary part-time by reason. We seek to determine whether the recessionary increase in involuntary part-time work is mostly the result of employed workers who are working part-time hours due to slack work, or instead if it is due to active job searchers not being able to find full-time work. To perform this decomposition, we start by writing the involuntary part-time rate as the sum of the rate of part-timers due to slack work $\left(i v_{t}^{s}\right)$ and the rate of part-timers because they cannot find a full-time jobs $\left(i v_{t}^{f}\right)$ :

$$
i v_{t}=i v_{t}^{s}+i v_{t}^{f}
$$

Then, the change from the beginning of the Great recession, denoted $t_{0}$, to some subsequent period $t$, can be expressed in this way:

$$
i v_{t}-i v_{t_{0}}=\sum_{\tau=t_{0}}^{t-1}\left(i v_{\tau+1}^{s}-i v_{\tau}^{s}\right)+\sum_{\tau=t_{0}}^{t-1}\left(i v_{\tau+1}^{f}-i v_{\tau}^{f}\right)
$$

and the ratio of $\sum_{\tau=t_{0}}^{t-1}\left(i v_{\tau+1}^{s}-i v_{\tau}^{s}\right)$ to $i v_{t}-i v_{t_{0}}$ quantifies the share of the increase in $i v_{t}$ accounted for by the increase in $i v_{t}^{s}$. Table 6 reports this ratio for various periods during and after the Great Recession. The top row considers the aggregate involuntary part-time rate, whereas the remaining ones are computed in specific groups of workers. On impact, the increase in the aggregate involuntary part-time employment rate is mostly accounted for by the increase in the share of workers who report slack work / poor business conditions (about 80\%). As time goes by, failure to find a full-time job grows in relative importance, although slack work still explains more than $56 \%$ of changes in the aggregate involuntary part-time at the end of the sample period. Despite the fact that the incidence of underemployment by reason differs across categories of workers (cf. columns 4 and 5 of Table 1), the much greater relative importance of "slack work" over "could only find part-time jobs" during this period is broadly in the same ballpark for most worker categories.

One way to interpret the observed shifts in the composition of the involuntary part-time is to consider evidence on workers' perception of ongoing labor market opportunities. A measure of the availability of good quality jobs in the U.S. economy as perceived by individuals polled by Gallup shows a very pronounced procyclicality. ${ }^{16}$ When the economy is performing poorly, workers perceive fewer good job opportunities, are less likely to engage in job search, and hence more likely to report slack work (those who remain part-time employed involuntarily). When economic activity recovers,

\footnotetext{
${ }^{16}$ Gallup polling data is available at www. gallup.com/poll.
} 
the opposite occurs: workers perceive good work opportunities, search more and if they remain in part-time employment involuntarily report they could not find a full-time job.

Table 6. Contribution of "slack work" to changes in the involuntary part time employment rate

\begin{tabular}{|c|c|c|c|c|c|c|}
\hline & \multicolumn{3}{|c|}{ During the Great Recession } & \multicolumn{3}{|c|}{ After the Great Recession } \\
\hline & $\begin{array}{l}6 \text { months } \\
(2008 \mathrm{~m} 06)\end{array}$ & $\begin{array}{l}12 \text { months } \\
(2008 \mathrm{~m} 12)\end{array}$ & $\begin{array}{l}18 \text { months } \\
(2009 \mathrm{~m} 06)\end{array}$ & $\begin{array}{l}1.5 \text { years } \\
(2010 \mathrm{~m} 12)\end{array}$ & $\begin{array}{c}3 \text { years } \\
(2012 \mathrm{~m} 06)\end{array}$ & $\begin{array}{c}4.5 \text { years } \\
(2013 \mathrm{~m} 12)\end{array}$ \\
\hline Total & 80.6 & 80.5 & 78.0 & 68.1 & 63.3 & 56.9 \\
\hline (a) Gender & & & & & & \\
\hline Men & 83.4 & 86.2 & 82.1 & 71.6 & 67.1 & 63.4 \\
\hline Women & 76.2 & 75.5 & 74.0 & 63.8 & 59.1 & 55.4 \\
\hline (b) Age & & & & & & \\
\hline 16 to 24 years & 71.8 & 69.9 & 65.4 & 52.3 & 45.0 & 45.1 \\
\hline 25 to 54 years & 79.5 & 82.4 & 80.5 & 71.8 & 67.1 & 59.3 \\
\hline 55 to 64 years & 102.0 & 84.5 & 86.6 & 74.8 & 71.6 & 74.5 \\
\hline (c) Education & & & & & & \\
\hline Less than high-school & 77.1 & 81.1 & 84.3 & 76.1 & 71.3 & 64.5 \\
\hline High-school graduates & 74.0 & 83.2 & 75.0 & 67.4 & 64.5 & 62.0 \\
\hline Some college & 73.9 & 71.0 & 73.5 & 64.3 & 58.8 & 49.5 \\
\hline College or higher education & 71.5 & 81.8 & 74.3 & 60.9 & 55.5 & 57.7 \\
\hline (d) Marital status & & & & & & \\
\hline Married & 76.3 & 78.6 & 79.3 & 72.0 & 67.3 & 63.6 \\
\hline Widowed; divorced; separated & 73.3 & 84.3 & 77.9 & 71.3 & 68.2 & 65.8 \\
\hline Single & 88.0 & 81.3 & 73.8 & 63.7 & 56.0 & 56.0 \\
\hline
\end{tabular}

NOTE: An entry in the table is the contribution of the share of workers who were working part-time involuntarily due to slack work to the evolution of the involuntary part-time employment share since the beginning of the Great Recession. Contributions are reported in percent.

\subsection{A structure to understand the effects of involuntary part-time work}

In this subsection we organize some of our empirical results so as to lay the foundations for the model developed in the next section. Ultimately, our aim is to use a theoretical framework that can be easily interpreted, that is necessarily stylized, but yet captures what we see as the key aspects of the empirical patterns of involuntary part-time risk.

First, in the model we focus only on three labor market states $(F, I$ and $U)$, ignoring transitions involving non-participation $(N)$ or voluntary part-time employment $(V)$. The quantitative importance of non-participation flows to the overall dynamics of involuntary part-time work is negligible (as reported in Table 4). This is not the case for voluntary part-time work: fluctuations to and from involuntary part-time work account for about $18 \%$ of the variation in involuntary part-time rate. The interpretation of these movements is moot in our empirical framework. In reality, someone classified as working part-time voluntarily may alter her desired labor supply in response to various shocks, which would show up in the data as a recorded move from $I$ to $V$, or vice versa. Similarly, through job-to-job transitions, a worker may move from a bad to a good part-time job (either because of better pay, hours or both), which triggers a change of labor market status from $I$ to $V$. Setting up a model that captures all these dimensions is beyond the scope of this paper. This said, the fact that the dynamics of $p(V \rightarrow I)$ and $p(I \rightarrow V)$ are very similar respectively to those of $p(F \rightarrow I)$ and $p(I \rightarrow F)$ suggests the distinction between these two employment states (full-time $F$ and voluntary part-time $V$ ) is smaller 
than the one separating them from involuntary part-time work.

Second, our model does not consider explicitly distinct reasons for involuntary part-time work. Nonetheless, approximate counterparts for these phenomena are present in the model implicitly. A worker who moves from unemployment to involuntary part-time work can be seen as someone who is working part-time because he could not find a full-time job. Similarly, a worker who is relocated to part-time from full-time employment can be considered as experiencing slack work in his current job.

Third, we build a model with no ex ante worker heterogeneity. The analysis in previous sections indicates that observed composition effects play a negligible role in the aggregate dynamics of involuntary part-time work. Our own previous work on part-time employment (BML) also provides a similar conclusion, as well as a vast literature on labor market dynamics (see e.g. Shimer, 2012).

Fourth and last, beyond differences in transition probabilities, workers in different labor market states differ in the time endowment they have to spend on nonmarket activities and their pecuniary returns. To inform these features of the model we use information on usual earnings and hours worked, available in the Outgoing Rotation groups of the CPS. A more detailed description of our findings is given in appendix B.5.

\section{Quantifying the effects of involuntary part-time work}

This section introduces a framework structured to extend our comparison of involuntary part-time work and unemployment. We seek to describe the trajectory of an individual whose labor market transitions can be informed by our data, and who faces a risk of working part-time involuntarily as well as a risk of being unemployed. Since the implications of the latter are well understood in terms of consumption-smoothing problems, we use a framework that can capture these implications. ${ }^{17}$

The framework we develop has two pillars, namely the job-search model and the incomplete market model. Both are standard and therefore the first subsection is trimmed to contain only an outline of the model. A complete, formal presentation is provided in Appendix C.

\subsection{Framework}

A worker makes transitions across full-time employment, part-time employment and unemployment.

\section{Preferences}

The worker is risk-averse and infinitely-lived. Her momentary utility function depends on both consumption $c$ and leisure time $h$, and she maximizes:

$$
\mathbb{E}_{0} \sum_{t=0}^{+\infty} \beta^{t} \frac{\left(c_{t}\left(\bar{h}-h_{t}\right)^{\eta}\right)^{1-\sigma}-1}{1-\sigma}
$$

\footnotetext{
${ }^{17}$ Similar models were used to analyze the welfare effects of unemployment insurance: see Hansen and İmrohoroğlu (1992), Abdulkadiroğlu, Kuruşçu and Şahin (2002) and Acemoglu and Shimer (2000).
} 
$\mathbb{E}_{0}$ denotes mathematical expectation conditional on information at time $0, \beta$ is the subjective discount factor, $\sigma$ is the coefficient of relative risk aversion, $\eta$ is the relative value of leisure compared to consumption and $\bar{h}$ is a time endowment. That is, given the amount of time $h$ spent working or searching for a job (details follow), leisure time is the remainder $\bar{h}-h$.

\section{Hours, wages and search}

There are two types of jobs available to the worker, part-time $(P)$ and full-time $(F)$, both of which consist of an exogenous bundle of wages and hours of work: $\left(w_{i}, h_{i}\right)$, with $i \in\{P, F\}$ indicating the job type. Notice that we do not assume that part-time work is involuntary. Rather, the involuntary nature of part-time work will be implied by our choice of parameter values.

The worker is either employed or unemployed and determines her own work opportunities by exerting search effort. Specifically, $h$ hours of search effort yields a probability $\lambda h$ to receive a job offer by the end of the period. A fraction $\phi_{P}$ of these offers are part-time jobs, and the worker can decide to turn down any job offer. Unemployed workers select hours of search effort within the interval $[0, \bar{h}]$ whereas employed workers can only choose hours of search effort within $\left[0, \bar{h}-h_{i}\right]$, where $i \in\{P, F\}$.

\section{Exogenous reallocation}

In employment $(F$ and $P$ ), there are exogenous reallocation shocks governed by the stochastic transition matrix:

$$
\Pi=\left[\begin{array}{lll}
\pi_{F, F} & \pi_{F, P} & \pi_{F, U} \\
\pi_{P, F} & \pi_{P, P} & \pi_{P, U}
\end{array}\right]
$$

The probabilities $\pi_{i, j}$ give a lower bound on the transitions between states $i$ and $j$, since in addition there are endogenous transitions across employment states coming from search and quit decisions.

\section{Insurance issues}

There are two sources of insurance to hedge against idiosyncratic risk: private and public. First, the worker has access to a single, risk-free asset $a$ which she can save but cannot borrow. The maximization of (6) is thus subject to a sequence of intertemporal budget constraints:

$$
c_{t}+a_{t+1} \leq(1+r) a_{t}+x_{t}^{d}
$$

and the constraint that $a_{t} \geq 0$ in every period $t$. In equation (8), $x_{t}^{d}$ denotes disposable earnings and $r$ is the real interest rate.

Second, there is an unemployment insurance system that (partially) insures against the risk of job loss. ${ }^{18}$ When the job is destroyed by the shocks $\pi_{P, U}$ or $\pi_{F, U}$, the worker is eligible to collect unemployment benefits $\theta_{1}$. These benefits expire with per period probability $\phi_{U}$. After exhaustion, she receives social assistance benefits $\theta_{0}<\theta_{1}$ forever. Access to unemployment benefits can be regained

\footnotetext{
${ }^{18}$ Given the partial equilibrium flavour of our framework, we do not introduce a tax on labor earnings to finance the provision of unemployment benefits and social assistance.
} 
only through a spell of employment. Finally, and importantly, we assume that the worker cannot quit to receive unemployment benefits. In particular, when a full-time position is transformed into a part-time one (which occurs with probability $\pi_{F, P}$ ), the worker can only choose between working part-time and moving to social assistance. ${ }^{19}$

We note that our framework effectively assumes that there is no public insurance against involuntary part-time work. This is consistent with our observation that workers in the U.S. are unlikely to benefit from alternative public insurance programs when part-time work is the only change to their employment status. Following this line of reasoning, in the next section we calibrate the model using data on workers who do not qualify for EITC.

\subsection{Parametrization/Calibration}

As highlighted in the experiments, the crux of our analysis relies on job availability parameters, $\lambda$ and $\phi_{P}$, and their implications for an individual with standard preference parameters, $\sigma, \eta, \beta$. Our approach, therefore, is to calibrate these parameters jointly and use observations of labor market outcomes to assign values to the remaining parameters. We interpret a period as one month.

\section{Parameters set externally}

The interest rate $r$ is 0.003 , i.e. 3.5 percent on an annual basis. This is in line with long-run averages of the real return on U.S. 10-year treasury note and is a standard value used in models of precautionary savings (see e.g. Gourinchas and Parker, 2002).

For earnings and hours worked, we note that the model allows for two normalizations: the time endowment $\bar{h}$ and full-time earnings $w_{F}$. We set both parameter values to 1.0. We use CPS data on earnings and hours to pin down values for $h_{F}, h_{P}$ and $w_{P}$ (see Appendix B.5). Assuming that individuals have $7 \times 14=98$ hours of substitutable time per week, we choose $h_{F}=0.429\left(h_{P}=0.245\right)$ to reproduce a workweek of 42 hours (24 hours) for full-time (part-time) workers. The part-time wage-penalty (the reduction in hourly wages attributable to part-time work) we estimate in our data is around $15 \%$. Thus, we set $w_{P}=0.485$ such that $w_{p} / h_{P}=0.85 w_{F} / h_{F}$.

To pin down values for the matrix $\Pi$, we use labor market data for non-married individuals without children. As already mentioned, these individuals are typically not eligible for EITC, which makes them a relevant empirical counterpart to the worker in our theoretical framework. Specifically, we use data before the period of the Great Recession as follows: (i) $\pi_{F, P}$ is set to the transition probability from full-time employment to involuntary part-time work, (ii) $\pi_{P, F}$ is set to the transition probability from involuntary part-time work to full-time employment at the same employer and (iii) $\pi_{F, U}$ (resp. $\left.\pi_{P, U}\right)$ is set to the transition probability from full-time employment (resp. involuntary part-time work)

\footnotetext{
${ }^{19}$ This extra nonemployment state (social assistance benefits) helps understand why, in this framework, the worker sometimes undertakes part-time work. Indeed, in the calibrated model, a part-time job yields earnings that are about twice lower than in full-time employment, and the replacement ratio of unemployment benefits is 45 percent of fulltime earnings. These differences would make it almost impossible to rationalize part-time work, given that individual preferences are ordered over both consumption and leisure.
} 
to unemployment. Since $\Pi$ is a stochastic matrix, we obtain:

$$
\Pi=\left[\begin{array}{lll}
0.978 & 0.009 & 0.014 \\
0.258 & 0.631 & 0.111
\end{array}\right]
$$

Finally, we use figures for the U.S. labor market reported in OECD (2007) to parametrize unemployment insurance and social assistance benefits. The average replacement ratios for these benefits are 45 and 5 percent, respectively, which dictates $\theta_{1}=0.45$ and $\theta_{0}=0.05$. $\phi$ is set to 0.167 to make the worker exhaust unemployment benefits after 26 weeks, in line with U.S. policies in normal times.

\section{Parameters set internally}

A key observation to pin down values for the remaining parameters, namely $\beta, \sigma, \eta, \lambda, \phi_{P}$, is the following equation from our framework:

$$
\frac{\eta c^{1-\sigma}}{(\bar{h}-h)^{1-\eta(1-\sigma)}}=\beta \lambda\left[\phi_{P} \max \left\{W_{P}-\bar{U}_{j}, 0\right\}+\left(1-\phi_{P}\right) \max \left\{W_{F}-\bar{U}_{j}, 0\right\}\right]
$$

In this equation, $W_{i}$ is the lifetime value of employment in $i \in\{P, F\}$, and $\bar{U}_{j}$ is the lifetime value of being unemployed with unemployment income $\theta_{j}$, with $j \in\{0,1\}$, by the end of the model period (see Appendix C). The right-hand side gives the expected returns to search effort in unemployment; the left-hand side of the equation is the marginal utility of the worker with respect to leisure. The interior solution for search effort satisfies this first order condition. Thus, equation (10) conveniently links preferences and job availability parameters.

Our approach is to choose values for $\sigma$ and $\eta$, and then calibrate jointly $\beta, \lambda, \phi_{P}$ to match the following targets: (i) the worker spends 50 percent of her time with a wealth to annual income ratio of 0.50 , (ii) her monthly job-finding rate from unemployment is 32.5 percent on average, and (iii) her transition rate from uninsured unemployment to part-time work is 6.25 percent on average. The ratio of wealth to annual income we select is slightly higher than the value of one-third reported in Kaplan and Violante (2014), which is motivated by the fact that our model precludes borrowing. Target (ii) is the job-finding rate computed in our data, i.e. the monthly transition probability to employment of unemployed, non-married individuals without children. Finally, target (iii) is also computed from the data using the observed transition probability from unemployment to involuntary part-time work $(U \rightarrow I)$. We use (iii) as a target for transitions out of uninsured unemployment because, in our framework, this makes the worker resemble the unemployed who would take on a part-time job because they cannot find a full-time position.

We choose $\sigma=2.0$ as a benchmark (we consider $\sigma=1$ and $\sigma=3$ for robustness), which is within the range of empirically plausible estimates of the coefficient of relative risk aversion (see Heathcote, Storesletten and Violante, 2009). As for the relative value of leisure, we use a low, intermediary and high value of leisure, namely: $\eta \in\{0.25,0.50,0.75\}$. Our calibration procedure yields: $\beta=0.9902$, $\lambda=0.4537, \phi_{P}=0.1792$ for the specification with $\sigma=2.0, \eta=0.50$. 


\section{Illustration of consumption behaviors}

Several features of the calibrated model give us confidence that it is appropriate to use it for quantitative inference. First, part-time work in the model is involuntary, in that the lifetime utility of the worker would always be higher in full-time employment than in part-time employment. This outcome results from a combination of the disutility of work, lower earnings in part-time employment and the fact the worker is too impatient to accumulate enough assets to prefer part-time over full-time work. Second, the model predicts that the worker dis-save during spells of part-time employment. Running down assets is, in models with precautionary savings, typically associated with unemployment. As illustrated in Figure 3, our framework also has this property, and the net savings decisions of the worker in part-time employment justifies the comparison we draw with unemployment.

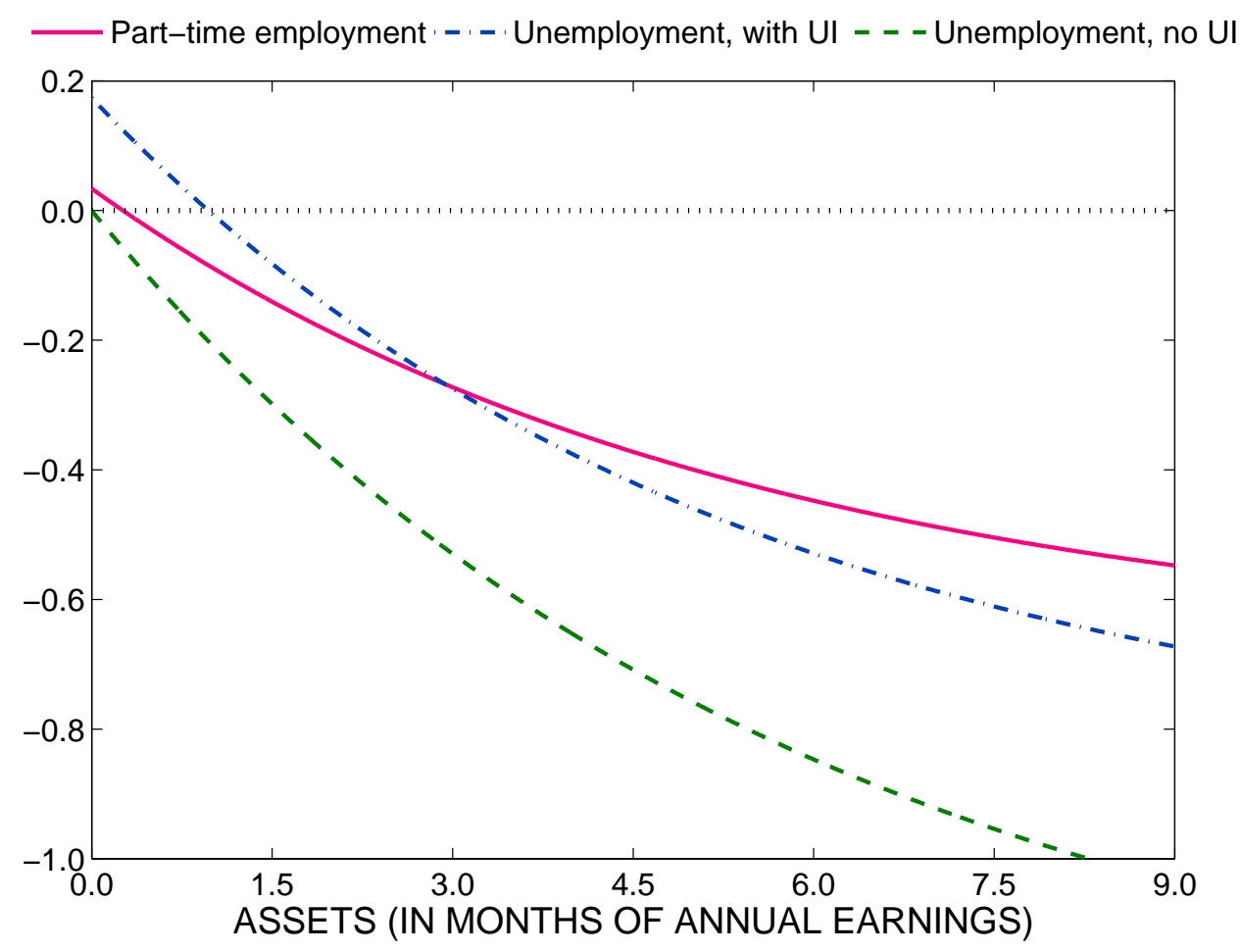

Figure 3. Net savings decisions in part-time employment (solid line), insured unemployment (dasheddotted line) and uninsured unemployment (dashed line)

The third, and perhaps more important reason why this framework is suitable for our purposes is that it captures the risk of unemployment well. Indeed, Table 7 below shows that the drop in consumption experienced on losing a full-time job (when wealth at the time of job loss amounts to one quarter of annual earnings) are similar to those observed in the data. For instance, when using $\eta=0.50$ for the relative value of leisure, the predicted drop in insured unemployment is $8 \%$, and the corresponding number in uninsured unemployment is $24 \%$. Both numbers are remarkably close to Gruber (1997): he reports a 6-8\% decrease in the first case and a $22 \%$ decrease in the second scenario. Of course, our model abstracts from dimensions of individual heterogeneity that could be present in the data and explains the figures reported by Gruber. Meanwhile, our calibration does not target these numbers. The fact that the model generates them endogenously suggests that it captures the key trade-offs faced by workers during unemployment. 
Table 7. Consumption drop following (full-time) job loss

\begin{tabular}{lccc}
\hline & $\eta=0.25$ & $\eta=0.50$ & $\eta=0.75$ \\
\hline Part-time employment & -5.42 & -5.57 & -5.79 \\
Insured unemployment & -13.55 & -8.25 & -5.11 \\
Uninsured unemployment & -29.64 & -24.15 & -21.42 \\
\hline
\end{tabular}

Note: An entry in the table is the change in consumption after losing employment in a full-time position, conditional on wealth at the time of job loss amounting to one quarter of annual earnings. All entries are reported in percent.

\subsection{Experiment I: Working part-time involuntarily vs. being unemployed}

In the first experiment, we seek to answer the question posed in the title of the paper. In keeping with our empirical analysis, we compare the risk of working part-time involuntarily to the risk of unemployment. There are three differences between those labor market states in our framework, namely: (i) the amount of earnings the worker receives, (ii) the role of hours supplied to the labor market (search vs. work) and (iii) the constraint on the choice of hours. To gain understanding of the role of each component, we gradually make part-time work resemble unemployment. First, we replace earnings in part-time work by unemployment benefits. Second, we assume that hours in parttime work play the same role as in unemployment; that is, we replace $\pi_{P, F}$ by $\lambda\left(1-\phi_{P}\right) h_{P}$. Third, we remove the constraint on hours in part-time work: we set $h_{P}=0$, which implies that we also remove exogenous transitions from part-time to full-time work. ${ }^{20}$

We first measure the relative contribution of each adjustment by comparing lifetime values in involuntary part-time work and unemployment. ${ }^{21}$ In our model, a worker prefers to be working parttime involuntarily rather than being unemployed for the following reasons:

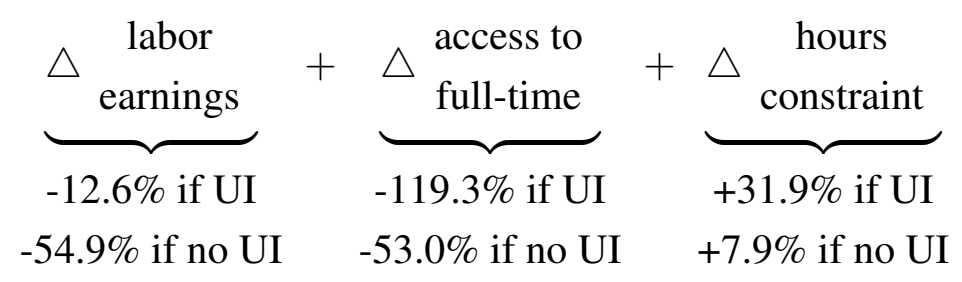

The difference in earnings account for $13 \%$ of the gap if we compare part-time work to insured unemployment, and $55 \%$ of the gap if we compare to uninsured unemployment. The second component is far more important in the comparison to insured unemployment as it accounts for $120 \%$ of the difference. The effect is smaller in the comparison to uninsured unemployment. Finally, not surprisingly, removing the constraint on hours makes unemployment more attractive. In the comparison with insured unemployment, this lowers the gap by $32 \%$. The corresponding number is $8 \%$ in the comparison with uninsured unemployment.

How can we explain the importance of the second component? A simple observation is that: $\lambda\left(1-\phi_{P}\right) h_{P}=0.454 \times(1.0-0.179) \times 0.245=0.091$ is the (exogenous) transition probability to full-time work that the worker would face during part-time employment if her hours $h_{P}$ were used for the purpose of search instead of work. This ought to be compared with the probability $\pi_{P, F}=0.258$ in (9), which is almost three times larger. In sum, given our estimates of job availability parameters,

\footnotetext{
${ }^{20}$ In the second and third adjustments, after changing the value of $\pi_{P, F}$, we rescale $\pi_{P, P}$ using $\pi_{P, p}=1.0-\pi_{P, F}-\pi_{P, U}$. This is because the value of $\pi_{P, U}$ remains unchanged throughout the experiments.

${ }^{21}$ We use the lifetime values at the asset level that amounts to one quarter of annual earnings.
} 
there is a premium in terms of gaining access to full-time employment when an individual is working part-time involuntarily rather than being unemployed.

While equation (11) is useful to understand the relative contribution of each effect, it does not inform us as to their magnitude. Therefore, in order to obtain more tangible figures, we run the following experiments. We draw two cohorts of full-time workers, one of which we reallocate into part-time employment in the first period of observation and use as our "control" group. For the second cohort, we replace earnings in part-time work with unemployment benefits and then we allocate the cohort to this modified state of involuntary part-time work. Both cohorts are followed for several periods and we keep track of their monthly outcomes. Finally, we estimate the treatment effect of displacement into the modified state of involuntary part-time work, which can be conditioned on the length of time since the shock occurred and on asset holdings at the time of the shock. We repeat the experiments with a third and fourth cohorts of workers, introducing each time the adjustments that underlie equation (11). ${ }^{22}$

The results of the numerical experiments are displayed in Table $8 .^{23}$ The outcome variable we focus on is cross-sectional utility, which we then express into percentage changes in consumption during the quarter after displacement (see Appendix C.4 for details). Consider for instance the number displayed in column 4 of the first row in Panel 1. If workers were reallocated to insured unemployment instead of part-time work, they would be worse off: their consumption during the first quarter would need to be raised by $5 \%$ to make them indifferent. The number is larger in uninsured unemployment (Panel 2) as their consumption would need to be increased by 19\%. Both numbers are empirically plausible, given the actual drop in consumption during unemployment discussed in the previous section. These effects vanish as we move to the second and third quarters after displacement. The reason is that, in the U.S. labor market as captured by our model, the dynamics of involuntary part-time work and unemployment are fast. After one quarter, the majority of workers from the control group have returned to full-time work, and a large fraction of workers from the treated group has also returned to full-time employment.

Next, when analyzing columns 1,2 and 3 , we note that access to full-time employment plays an important role in all instances. This is the key finding of the experiment: the fact that $\pi_{P, F}$ is considerably higher than the transition rate to full-time work that would be implied $h_{P}$ has important welfare implications: losing the premium associated $\pi_{P, F}$ amounts to a loss of $4-5 \%$ in consumption during the first quarter of a spell of involuntary part-time work. Our interpretation is that $\pi_{P, F}$ captures an alternative reallocation channel compared to job search. Indeed, the parameters for job availability are based on equation (10), i.e. on the behavior of unemployed workers. If involuntary part-time workers were subjected to the same technology to return to full-time work, they would move less quickly and suffer more long-lasting decreases in consumption. Notice that the 4-5\% loss in quarterly consumption we report requires combining data with our theoretical framework. Indeed, this number depends on the parameters we obtain from the data, in particular the transition probability from invol-

\footnotetext{
${ }^{22}$ In these experiments, as in the decomposition performed in equation (11), we re-compute optimal decisions and lifetime values after changing any parameter of the model. Therefore the individual always takes into account changes to the economic environment, which she interprets as permanent changes.

${ }^{23}$ In the experiment, we focus on a cohort of workers with wealth amounting to one quarter of annual earnings at the time of displacement. Since the results are similar when we change the relative value of leisure, we focus on $\eta=0.50$ and defer the results based on $\eta=0.25$ and $\eta=0.75$ to Appendix C.5.
} 
Table 8. Welfare comparison: involuntary part-time work vs. unemployment $(\sigma=2.0, \eta=0.50)$

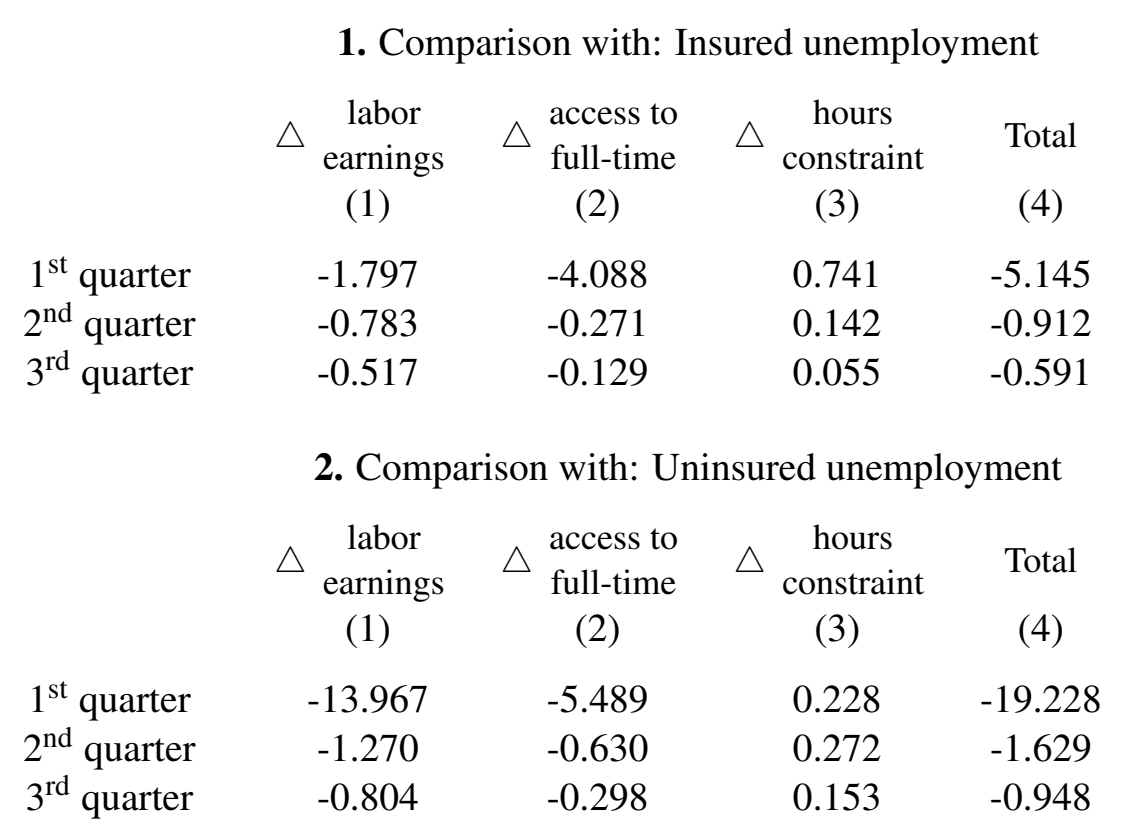

NOTE: The upper panel of the table compares part-time employment with insured unemployment. The lower panel of the table compares part-time employment with uninsured unemployment. An entry in each panel is the treatment effect of reducing labor earnings in part-time employment (Column 1), changing the exogenous probability of moving into full-time employment (Column 2), removing the constraint on hours worked (Column 3), and finally the cumulated sum of these effects (Column 4). The treatment effects are computed using cohorts of workers whose wealth amounts to one quarter of annual earnings at the time of job displacement. The effects are reported as averages over each quarter (up to the 3rd quarter) following the displacement shock. The outcome variable is cross-sectional utility, converted into consumption equivalent units. All entries are reported in percent.

untary part-time to full-time work at the same employer, and on the optimal behavior implied by the preferences of our framework.

\subsection{Experiment II: Cyclicality in the risk of involuntary part-time work}

Having analyzed the effects at the individual level, we turn to the other important theme of our analysis, namely cyclical fluctuations. In this section, our goal is to measure the effects of such fluctuations in the risk of working part-time involuntarily, as well as the increased incidence of involuntary parttime work observed since the Great Recession.

To capture business cycle fluctuations, we extend the framework presented in the previous sections to allow for an aggregate state variable, namely

$$
z \in\left\{z_{b}, z_{g}\right\}
$$

That is, the economy is either in a good state $\left(z_{g}\right)$ or in a bad state $\left(z_{b}\right)$. We assume that $z$ is governed by a symmetric Markov process with parameter $\rho_{z}$. This construct is borrowed from Krusell et al. (2009, 2015). In particular, Krusell et al. (2015) analyze the effects of business cycle fluctuations in job availability on gross worker flows between employment, unemployment and nonparticipation. 
We adopt their specification and choose $\rho_{z}=0.975$.

Next, we posit that the business cycle affects the stochastic matrix $\Pi$ (cf. equation (7)). Our focus is on fluctuations in $\pi_{F, P}$ and $\pi_{P, F}$ and we allow for negatively correlated shocks to these transition probabilities. In somewhat less formal notations, we use $\pi_{F, P}(z)=\pi_{F, P}\left(1+\varepsilon_{F, P}\right)\left(=\pi_{F, P}\left(1-\varepsilon_{F, P}\right)\right)$ if $z=z_{b}$ (if $z=z_{g}$ ), and $\pi_{P, F}(z)=\pi_{P, F}\left(1-\varepsilon_{P, F}\right)\left(=\pi_{P, F}\left(1+\varepsilon_{P, F}\right)\right)$ if $z=z_{b}$ (if $z=z_{g}$ ). This specification captures the effects of the business cycle with two parameters only: $\varepsilon_{F, P}$ and $\varepsilon_{P, F} . \varepsilon_{F, P}=0$ and $\varepsilon_{P, F}=0.05$ are used as benchmark values to reproduce tranquil economic times. We allow for variations in $\pi_{P, F}$ because of the high correlation between $I \rightarrow F$ transitions and the job-finding rate, which is a very cyclical variable.

In Table 9, we study the implications of increasing $\varepsilon_{P, F}$ to values observed in the data. To be precise, the numbers in the table are percentage changes in the lifetime consumption of an increase in the variance of $\pi_{F, P}$ (see Appendix C.4 for details). Given that our benchmark is a constant probability, these experiments measure the cost of business cycle fluctuations accruing from transitions to involuntary part-time work. We contrast the effects by looking at deviations around a steady-state value of $\pi_{F, P}$ of $1 \%$ vs. a steady-state value of $2 \%$, which seem to capture, respectively, the U.S. labor market experience before and after the Great Recession (cf. Figures $2 \mathrm{a}$ and $2 \mathrm{c}$ ).

There are two main findings in Table 9. First, the negative correlation between $\pi_{P, F}$ and $\pi_{F, P}$ is quantitatively important to generate welfare losses from involuntary part-time work. In recessions, the probability of working part-time involuntarily rises, but the welfare implications would be negligible if the fast dynamics of involuntary part-time work were to remain unaltered. This finding echoes the result that distinguishing short- from long-term unemployment is paramount to measure the cost of business cycle fluctuations (Krusell et al., 2009). Second, fluctuations in involuntary part-time work entail some non-negligible welfare losses. However, these are an order of magnitude lower than the welfare losses that would justifying introducing a specific policy instrument to mitigate the effects of cyclical fluctuations. We observe that, in the most extreme scenario (Panel 2, $\eta=0.75, \varepsilon_{F, P}=0.15$, $\varepsilon_{P, F}=0.40$ ), the welfare losses remains below one-third of a percentage point. ${ }^{24}$ This number is an order of magnitude lower than the gain from eliminating business cycle fluctuations in Krusell et al. (2009). It underscores the conclusion that involuntary part-time work is probably not bad because some workers may be covered by EITC, and based on our experiments those who are not are unlikely to suffer large welfare losses.

\section{Discussion}

The purposefully simple and partial equilibrium nature of our model implies that our conclusions do not take into account potentially relevant dimensions and general equilibrium effects. We measure the effects of increasing the variance of $\pi_{F, P}$ relative to a baseline environment where $\pi_{F, P}$ does not fluctuate, but this baseline ignores some dimensions and effects that could change our quantitative results. Here we mention a few of those that seem particularly relevant to us.

First, the model ignores the fact that, by temporarily transforming a full-time job into a part-time position, a worker-firm pair may avoid destroying a valuable employment relationship. That is, in addition to sparing the cost of creating a new vacancy, the option of part-time work may help preserve a

\footnotetext{
${ }^{24}$ This result is robust to our choice of preferences for the utility component of leisure. As shown in Appendix C.5, the result is also robust to changes in the coefficient of relative risk aversion.
} 
Table 9. Welfare effects of an increase in the cyclical risk of involuntary part-time work $(\sigma=2.0)$

\begin{tabular}{|c|c|c|c|c|c|c|}
\hline & \multicolumn{6}{|c|}{ 1. Deviations around $\pi_{F, P}=0.01$} \\
\hline & \multicolumn{2}{|c|}{ a. $\eta=0.25$} & \multicolumn{2}{|c|}{ b. $\eta=0.50$} & \multicolumn{2}{|c|}{ c. $\eta=0.75$} \\
\hline & $\begin{array}{c}\varepsilon_{F, P}=0.20 \\
\text { (1) }\end{array}$ & $\begin{array}{c}\varepsilon_{F, P}=0.40 \\
(2)\end{array}$ & $\begin{array}{c}\varepsilon_{F, P}=0.20 \\
\text { (1) }\end{array}$ & $\begin{array}{c}\varepsilon_{F, P}=0.40 \\
(2)\end{array}$ & $\begin{array}{c}\varepsilon_{F, P}=0.20 \\
\quad(1)\end{array}$ & $\begin{array}{c}\varepsilon_{F, P}=0.40 \\
(2)\end{array}$ \\
\hline$\varepsilon_{P, F}=0.05$ & {$[-0.013,-0.012]$} & {$[-0.021,-0.021]$} & {$[-0.019,-0.018]$} & {$[-0.030,-0.029]$} & {$[-0.023,-0.021]$} & {$[-0.036,-0.035]$} \\
\hline$\varepsilon_{P, F}=0.10$ & {$[-0.039,-0.035]$} & {$[-0.062,-0.058]$} & {$[-0.054,-0.051]$} & {$[-0.088,-0.083]$} & {$[-0.070,-0.065]$} & {$[-0.111,-0.103]$} \\
\hline \multirow[t]{4}{*}{$\varepsilon_{P, F}=0.15$} & {$[-0.070,-0.064]$} & {$[-0.110,-0.101]$} & {$[-0.099,-0.093]$} & {$[-0.155,-0.146]$} & {$[-0.131,-0.123]$} & {$[-0.199,-0.186]$} \\
\hline & \multicolumn{6}{|c|}{ 2. Deviations around $\pi_{F, P}=0.02$} \\
\hline & \multicolumn{2}{|c|}{ a. $\eta=0.25$} & \multicolumn{2}{|c|}{ b. $\eta=0.50$} & \multicolumn{2}{|c|}{ c. $\eta=0.75$} \\
\hline & $\begin{array}{c}\varepsilon_{F, P}=0.20 \\
\text { (1) }\end{array}$ & $\begin{array}{c}\varepsilon_{F, P}=0.40 \\
(2)\end{array}$ & $\begin{array}{c}\varepsilon_{F, P}=0.20 \\
\text { (1) }\end{array}$ & $\begin{array}{c}\varepsilon_{F, P}=0.40 \\
(2)\end{array}$ & $\begin{array}{c}\varepsilon_{F, P}=0.20 \\
\text { (1) }\end{array}$ & $\begin{array}{c}\varepsilon_{F, P}=0.40 \\
(2)\end{array}$ \\
\hline$\varepsilon_{P, F}=0.05$ & {$[-0.019,-0.018]$} & {$[-0.020,-0.018]$} & {$[-0.026,-0.025]$} & {$[-0.028,-0.025]$} & {$[-0.030,-0.029]$} & {$[-0.032,-0.029]$} \\
\hline$\varepsilon_{P, F}=0.10$ & {$[-0.061,-0.057]$} & {$[-0.089,-0.085]$} & {$[-0.086,-0.083]$} & {$[-0.125,-0.122]$} & {$[-0.109,-0.102]$} & {$[-0.153,-0.147]$} \\
\hline$\varepsilon_{P, F}=0.15$ & {$[-0.114,-0.105]$} & {$[-0.170,-0.159]$} & {$[-0.161,-0.154]$} & {$[-0.239,-0.229]$} & {$[-0.209,-0.196]$} & {$[-0.300,-0.283]$} \\
\hline \multicolumn{7}{|c|}{$\begin{array}{l}\text { NOTE: The table reports the effects of an increase in the cyclical risk of involuntary part-time employment. The upper } \\
\text { panel of the table }(1 \mathrm{a}, 1 \mathrm{~b}, 1 \mathrm{c}) \text { shows the effects of deviations around the monthly transition probability } \pi_{F, P}=0.01 \text {. } \\
\text { The lower panel of the table }(2 \mathrm{a}, 2 \mathrm{~b}, 2 \mathrm{c}) \text { shows the effects of deviations around the monthly transition probability } \\
\pi_{F, P}=0.02 \text {. Panels } \mathrm{Xa}, \mathrm{Xb}, \mathrm{Xc} \text { report results based on a low, middle and high utility of leisure, respectively. An en- } \\
\text { try in each panel shows the range of welfare effects computed at different levels of asset holdings. The welfare effects } \\
\text { measure the percentage change in lifetime consumption of moving from an environment with } \varepsilon_{P, F}=\varepsilon_{F, P}=0 \text { to an } \\
\text { environment with } \varepsilon_{P, F}>0 \text { and } \varepsilon_{P, F}>0 \text {. All entries are reported in percent. }\end{array}$} \\
\hline
\end{tabular}

good match between a worker and a firm and other match-specific components accumulated since the beginning of the job spell. Second, we abstract from effects operating along the job creation margin. For instance, in more volatile industries, temporary part-time jobs may be instrumental in smoothing out adverse shocks. Without the possibility of using part-time employment in times of slack demand conditions, these industries may create fewer jobs, which would reduce output, consumption and welfare. These two dimensions require a theory of the causes of involuntary part-time work, which is beyond the scope of this paper but remains high on our research agenda.

Finally, our analysis ignores several effects of labor market disruptions that would make involuntary part-time work and/or unemployment more harmful. Unemployment is typically associated with human capital losses, higher divorce rates and lower emotional well-being, to name but a few of its adverse consequences. It is not known whether involuntary part-time work leaves the same scars. These dimensions pertain to the consequences of involuntary part-time work. Investigating its effects on a larger set of labor market outcomes is a natural follow up to our analysis.

\section{Conclusion}

This paper starts by making the case that the recent experience of the U.S. labor market warrants a close look at involuntary part-time work. The empirical strategy we pursued to understand the relevance of this labor market risk was to compare it systematically to unemployment. Our joint characterization of the involuntary part-time and unemployment rates showed that, despite their strong correlation, their dynamic behavior is quite distinct. In a nutshell, while fluctuations in involuntary 
part-time work are driven by full-time employment inflows, those of unemployment are dominated by outflows to non-participation and full-time employment. Therefore, in contrast to unemployment, the recessionary increase in involuntary part-time work does not seem to entail a risk of long spells of involuntary part-time employment. We made use of a theoretical framework to interpret further and quantify the implications of involuntary part-time on workers' employment trajectories. The conclusion from our analysis is that, relative to unemployment, involuntary part-time work entails a premium in access to full-time work, which has non-trivial implications for welfare.

As involuntary part-time work becomes pervasive in the U.S. labor market, it is likely that related public insurance programs, such as short-time compensation schemes, will gain importance in policy debates. Our analysis focuses on the implications of involuntary part-time work at the individual level and does not address its macroeconomic consequences, but nevertheless we can provide some observations. In our view, whether public intervention targeted towards involuntary part-time work would necessarily lead to gains in terms of social welfare is unclear. There are arguably a number of additional parameters to be considered. For instance, there may be a significant degree of moral hazard regarding the number of hours worked and the voluntary/involuntary nature of a reduction in the schedules of working hours. Our framework also highlighted that an assessment of the welfare costs of involuntary part-time work relies on fundamental interactions with the risk of unemployment and public insurance against this risk (see also Burdett and Wright, 1989). That makes it all the more important to conduct a complete welfare analysis of the introduction of short-time compensation schemes in the context of the joint design of public insurance against unemployment and involuntary part-time work. This in turn will bring subtleties of its own to the problem. For example, in the U.S., where unemployment insurance is experience-rated, involuntary part-time work may provide a way for employers to smooth out an adverse shock while escaping unemployment taxes. We leave these questions for future work.

The findings we report in this paper complement our own previous work on part-time employment. In BML we showed that fluctuations in the intensive margin (hours per worker) are chiefly driven by movements in the part-time employment share, and that these adjustments occur mostly within, rather than across, employers. By and large, these patterns are similarly present (if not reinforced) when looking at involuntary part-time work. The advantage of focusing on involuntary part-time work is that we can readily interpret it as an undesirable labor market state, and draw a close parallel to unemployment. 


\section{A Data appendix}

This appendix complements Section 2 and 3 of the paper: it contains details about our data and adjustment procedures.

\section{A.1 Series published by the BLS}

In order to obtain the long-run time series displayed on Figure 1, we combine information from the published series of the Bureau of Labor Statistics (BLS) and two yearly time series of the March CPS assembled by BML. The BLS time series of part-time employment are based on the CPS and therefore they are not entirely reliable before 1994. The standard definition (post 1994) classifies as part-time workers those who report less than 35 usual weekly hours worked at their primary job, whereas before 1994 CPS respondents only reported whether they usually work less than 35 weekly hours in total. This generates a number of measurement problems. To take one example, those working part-time at two different jobs are likely to be counted as full-time workers in the pre-1994 files of the CPS, thereby underestimating the number of part-time jobs. Conversely, in the pre-1994 files of the CPS, involuntary part-time work is defined in relation to the reference week of the survey, not in relation to the job. In general, this results in an overestimate of the number of involuntary part-time workers before 1994 (since actual hours are often lower than usual hours).

The details of our adjustment procedure are the following:

1. We retrieve series LNS12600000 and LNS12032194 from the BLS website. These monthly times series count the number of part-time workers (from January 1968 onwards) and those working part-time involuntarily (from May 1955 onwards), respectively. ${ }^{25}$

2. Using the March CPS files, we construct time series for the aggregate part-time and involuntary part-time employment rates. We classify CPS respondents as part-timers if they work part-time in more than 50 percent of their annual number of working weeks. ${ }^{26}$

3. We adjust the stocks from the BLS time series so that the implied yearly rates matches the corresponding value from the March CPS. This amounts to computing an adjustment factor for each BLS time series that is common across all months of a given year. ${ }^{27}$ Finally, since the March CPS data begins in 1975 only, we use the average of these adjustment factors for the years 1975-1977 to adjust any pre-1975 data. ${ }^{28}$

Figure A1 plots the series of unadjusted and adjusted stocks of part-time workers and involuntary parttime workers. As can be observed on those graphs, there is a discrepancy around the 1994 redesign of the survey. Our adjustment procedure appears successful in addressing the break in the series. Finally, the unadjusted and adjusted series confirm our conjecture of a downward (resp. upward) bias in the series LNS12600000 (resp. LNS12032194) published by the BLS.

\footnotetext{
${ }^{25}$ Thus, the time-series of involuntary part-time work displayed in Figure 1 is the adjusted series LNS12032194 divided by the civilian labor force level LNS11000000.

${ }^{26}$ In BML we used two alternative measurements of the part-time employment rate based on the March CPS, and show that both are consistent with the one based on monthly CPS files after 1994. Here we use one of these definitions.

${ }^{27}$ These adjustment factors are available from the authors upon request.

${ }^{28}$ The March CPS data is available from 1976 onwards and each yearly files contains information about employment in the previous calendar year.
} 

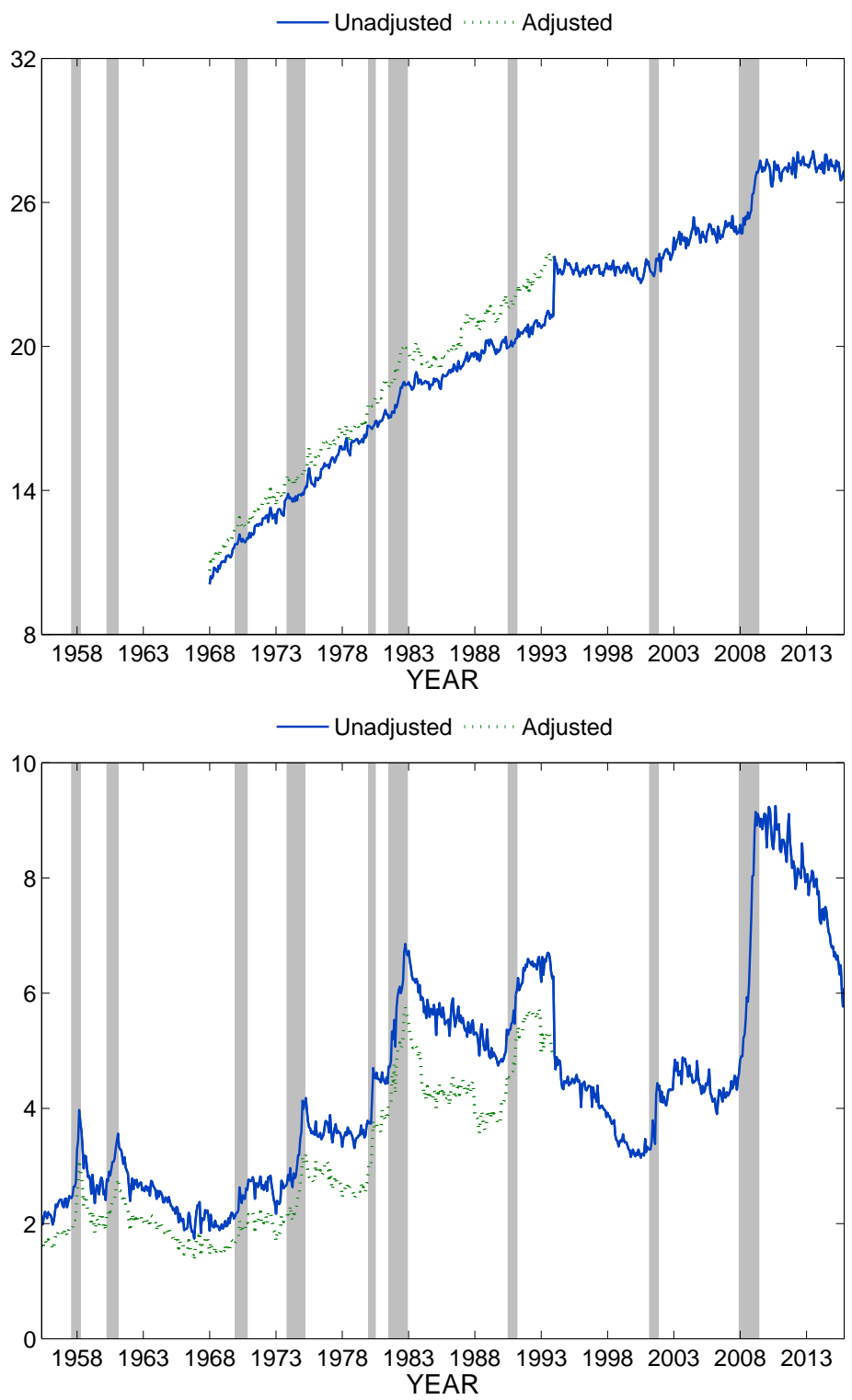

Figure A1. Unadjusted and adjusted series of labor market stocks: Numbers working in part-time jobs (top) and Numbers working part-time involuntarily (bottom)

Seasonally-adjusted time-series. Figures are reported in million workers. Gray-shaded areas indicate NBER recession periods.

\section{A.2 Microdata from the CPS}

\section{Recoding transitions between $V$ and $I$}

We use monthly data from the CPS in order to construct and analyze labor market flows from 1994 onwards. The CPS has a rotating panel structure which we use in various ways. First, we link CPS respondents in two consecutive months using household and personal identifiers from the non-rotation groups as well as an age/sex/race filter. We then repeat this procedure sequentially so as to match individuals across four consecutive months (the longest period of time in which CPS respondents are interviewed consecutively). Ultimately, we seek to use the longitudinal information from the first to the fourth month of the interview to minimize measurement error in recorded transitions between 
months 2 and 3 of the interview. ${ }^{29}$ Indeed, a well-known problem is that even small amounts of reporting error in individual labor market status in a cross-section can produce large changes in measured flows. We are especially concerned with transitions between voluntary $(V)$ and involuntary $(I)$ part-time work, which appear spuriously common in the raw data.

To deal with this issue we adapt the practical approach suggested by Elsby, Hobijn and Şahin (2015). We use a rule of thumb to detect and correct suspicious labor market status in months 2 and 3 of the interview. Specifically, we recode labor force status that would imply a transition between $V$ and $I$ as follows:

\begin{tabular}{cccc} 
Raw data & Recoded & Raw data & Recoded \\
\hline$F \rightarrow V \rightarrow I \rightarrow V$ & $F \rightarrow V \rightarrow V \rightarrow V$ & $F \rightarrow I \rightarrow V \rightarrow I$ & $F \rightarrow I \rightarrow I \rightarrow I$ \\
$V \rightarrow V \rightarrow I \rightarrow V$ & $V \rightarrow V \rightarrow V \rightarrow V$ & $I \rightarrow I \rightarrow V \rightarrow I$ & $I \rightarrow I \rightarrow I \rightarrow I$ \\
$U \rightarrow V \rightarrow I \rightarrow V$ & $U \rightarrow V \rightarrow V \rightarrow V$ & $U \rightarrow I \rightarrow V \rightarrow I$ & $U \rightarrow I \rightarrow I \rightarrow I$ \\
$N \rightarrow V \rightarrow I \rightarrow V$ & $N \rightarrow V \rightarrow V \rightarrow V$ & $N \rightarrow I \rightarrow V \rightarrow I$ & $N \rightarrow I \rightarrow I \rightarrow I$ \\
$V \rightarrow I \rightarrow V \rightarrow F$ & $V \rightarrow V \rightarrow V \rightarrow F$ & $I \rightarrow V \rightarrow I \rightarrow F$ & $I \rightarrow I \rightarrow I \rightarrow F$ \\
$V \rightarrow I \rightarrow V \rightarrow V$ & $V \rightarrow V \rightarrow V \rightarrow V$ & $I \rightarrow V \rightarrow I \rightarrow I$ & $I \rightarrow I \rightarrow I \rightarrow I$ \\
$V \rightarrow I \rightarrow V \rightarrow U$ & $V \rightarrow V \rightarrow V \rightarrow U$ & $I \rightarrow V \rightarrow I \rightarrow U$ & $I \rightarrow I \rightarrow I \rightarrow U$ \\
$V \rightarrow I \rightarrow V \rightarrow N$ & $V \rightarrow V \rightarrow V \rightarrow N$ & $I \rightarrow V \rightarrow I \rightarrow N$ & $I \rightarrow I \rightarrow I \rightarrow N$
\end{tabular}

Like Elsby, Hobijn and Şahin (2015), we recode transitions between $N$ and $U$ (the procedure amounts to replacing $V$ by $N$ and $U$ by $I$ in the above table) in order to improve the analysis of fluctuations in the unemployment rate. Notice that we make no attempt to recode "cycles" such as $V \rightarrow I \rightarrow V \rightarrow I$ and $I \rightarrow V \rightarrow I \rightarrow V$ (likewise, $N \rightarrow U \rightarrow N \rightarrow U$ and $U \rightarrow N \rightarrow U \rightarrow N$ ).

Figure A2 plots the raw probabilities and the fraction of transitions from $I$ to $V$ (top) and from $V$ to $I$ (bottom) that we end up discarding (dotted line). On average, about $50 \%$ of the transitions observed between months 2 and 3 are deemed suspicious when checked against the information provided in months 1 and 4 of interview. This figure seems relatively high, yet it is in line with estimates of measurement error in other labor market transitions computed using the monthly CPS. For example, Moscarini and Thomsson (2007) report that the unadjusted occupational mobility rate in the monthly CPS files for the years 1979-1993 is 34\%, whereas the adjusted rate is less than 4\%. Second, and interestingly, we find that the amount of noise is roughly identical for $I \rightarrow V$ and $V \rightarrow I$ transitions, although the levels of the raw transition probabilities are very different. Finally, we find little to no evidence of cyclicality in the amount of measurement error. As a result, the clear cyclical patterns of the raw transition probabilities are also present in their adjusted counterparts.

\section{Other adjustments}

We subject our time series derived from the monthly files of the CPS to several consecutive adjustments. Firstly, we adjust for seasonality using the Census Bureau's X-13ARIMA-SEATS program

\footnotetext{
${ }^{29} \mathrm{By}$ months one, two, three and four, we refer to those from the four-months period of consecutive interviews. Thus, although not apparent in this terminology, we use respondents from rotation groups 1 and 3 as well as rotation groups 5 to 7 . This implies that an individual who remains in the survey for a complete 16-months period (two periods of four consecutive interviews with a 8-months break period between them) can contribute to our computations twice.
} 

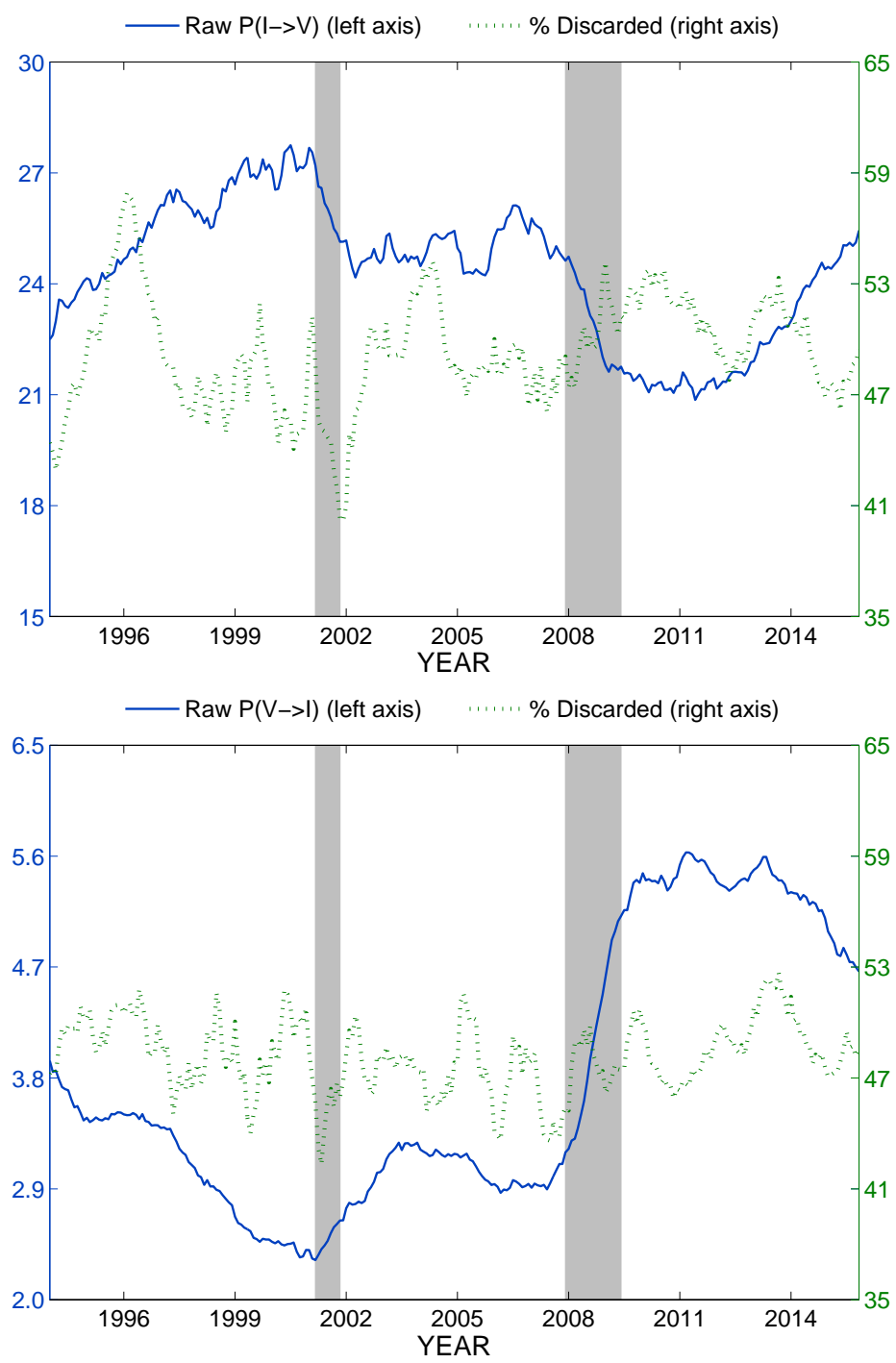

Figure A2. Adjusting labor market transitions: Raw transition probabilities and fraction turned down by the recoding procedure for $I \rightarrow V$ (top) and $V \rightarrow I$ (bottom) transitions

Seasonally-adjusted time-series. Gray-shaded areas indicate NBER recession periods.

(see: https://www.census.gov/srd/www/x13as/). Next, we adjust the time series of labor market flows for margin error, so as to reconcile them with the time series of labor market stocks. The margin-error adjustment is particularly important in our application, since our recoding procedure implies matching CPS respondents over four consecutive months, which amplifies sample attrition and hence potential biases. Last, we correct transition probabilities to account for time-aggregation bias (Shimer, 2012). Fortunately, in our sample, the conditions on the eigenvalues of the discretetime transition matrix $\boldsymbol{M}_{t}$ are always satisfied, which allows us to recover and report bias-adjusted transition probabilities. 


\section{B Additional empirical results}

\section{B.1 More business-cycle moments}

To complement our analysis, in this section we report standard business cycle moments for the involuntary part-time employment and unemployment rates. We analyze three different periods: (i) the longest period covered by our time series (1968q1-2015q3), (ii) the same period from which we exclude the Great Recession (1968q1-2007q3) and (iii) the period covered by our CPS data (1994q12015q3). The comparison of (i) and (ii) isolates the lack of correlation between productivity and labor market variables observed during the Great Recession. Table B1 supports the claim that the involuntary part-time employment rate is as good an indicator of labor market activity as the unemployment rate. Indeed, the involuntary part-time employment rate exhibits higher standard deviations, similar auto-correlations and is more strongly (negatively) correlated with productivity. Finally, just like the unemployment rate, the involuntary part-time employment rate was less correlated with productivity during the Great Recession.

Table B1. Involuntary part-time employment rate vs. unemployment rate: Business cycle behavior

\begin{tabular}{|c|c|c|c|c|c|c|}
\hline \multirow{3}{*}{$\begin{array}{l}\text { Start: } \\
\text { End: }\end{array}$} & \multicolumn{3}{|c|}{ Involuntary part-time rate } & \multicolumn{3}{|c|}{ Unemployment rate } \\
\hline & $1968 \mathrm{q} 1$ & 1968q1 & 1994q1 & 1968q1 & 1968q1 & 1994q1 \\
\hline & $2015 \mathrm{q} 3$ & $2007 \mathrm{q} 3$ & $2015 q 3$ & $2015 q 3$ & $2007 q 3$ & $2015 q 3$ \\
\hline$\sigma($ & 0.22 & & & 0.184 & 0.156 & 0.201 \\
\hline $\operatorname{Corr}\left(x, x_{-1}\right.$ & 0.946 & 0.929 & 0.965 & 0.962 & 0.952 & 0.973 \\
\hline $\operatorname{Corr}(x, p)$ & -0.344 & -0.403 & -0.077 & -0.246 & -0.328 & 0.024 \\
\hline
\end{tabular}

Note: $\sigma(x)$ : Standard deviation; $\mathbb{C o r r}\left(x, x_{-1}\right)$ : Auto-correlation; $\mathbb{C o r r}(x, p)$ : Correlation with productivity. $p$ : seasonally adjusted quarterly series of real output per person in the non-farm business sector (PRS85006163) of the Bureau of Labor Statistics. Quarterly time-series taken in log as deviation from a HP trend with smoothing parameter $10^{5}$.

\section{B.2 Composition effects (or the lack thereof)}

Subsection 3.2 portrays the evolution of involuntary part-time work during the Great Recession. In that section, we mention that composition effects - changes in employment of various sub-groups of the workforce with different involuntary part-time rates - cannot explain the recessionary increase in overall involuntary part-time work. We substantiate this claim below. Consider first the computation of the involuntary part-time employment rate; this is the weighted sum:

$$
i v_{t}=\sum_{g} \omega_{t}^{g} i v_{t}^{g}
$$

where $\omega_{t}^{g}$ is the share of employed persons in some sub-group $g$ and $i v_{t}^{g}$ is the involuntary part-time employment share within this group. This equation is the basis for constructing a chain-weighted series of the contribution of changes in the shares $\omega_{t}^{g}$ to the evolution of the aggregate involuntary part-time employment rate $i v_{t}$. Denoting by $t_{0}$ the beginning of the Great Recession, the proposed 
Table B2. Actual and counterfactual changes in the involuntary part time employment rate

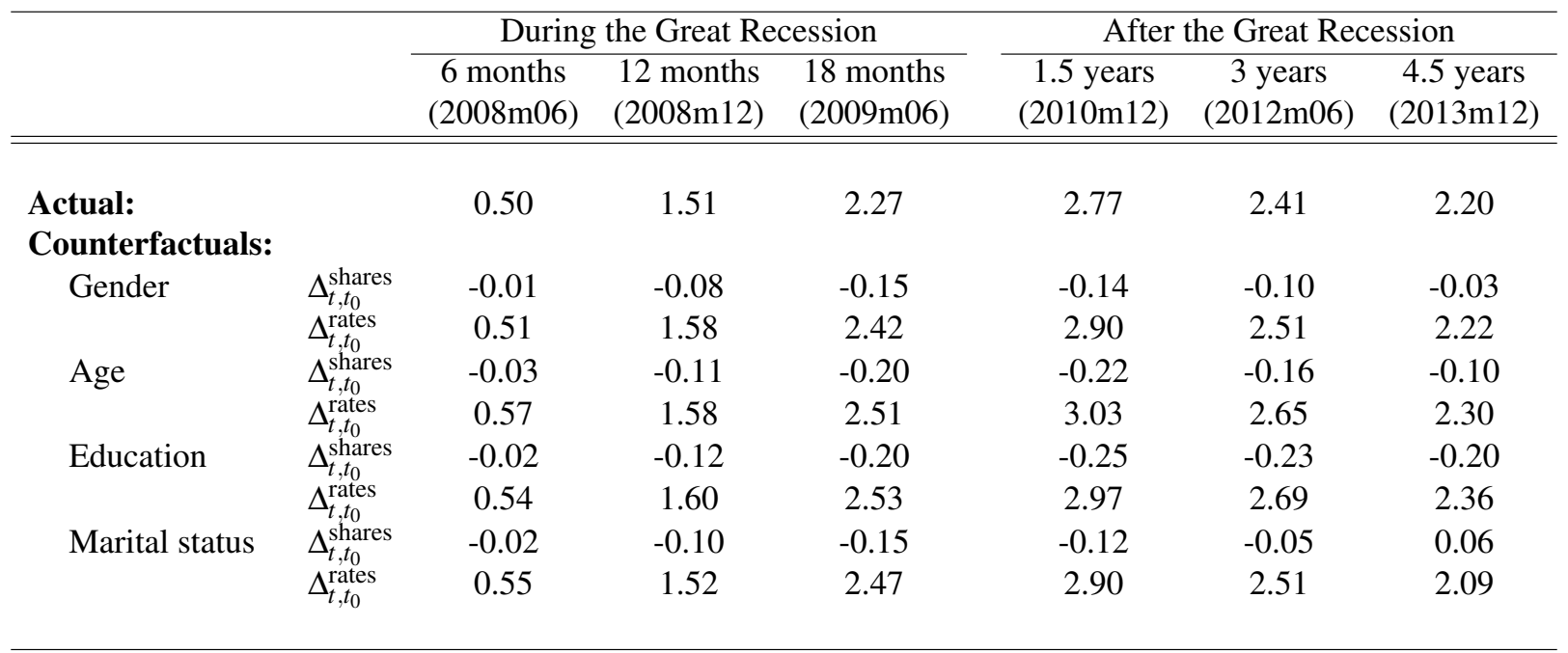

NoTE: CPS data. All entries in the table are reported in percent. The counterfactuals for age are based on 3 groups: 16 to 24 years; 25 to 54 years; 55 to 64 years. The counterfactuals for education are based on 4 groups: less than highschool; high-school graduates; some college; college or higher education. The counterfactuals for marital status are based on 3 groups: married; widowed, divorced or separated; single.

chain-weighted series is:

$$
\Delta_{t, t_{0}}^{\text {shares }} \equiv \sum_{\tau=t_{0}}^{t-1} \sum_{g}\left(\omega_{\tau+1}^{g}-\omega_{\tau}^{g}\right) \frac{i v_{\tau}^{g}+i v_{\tau+1}^{g}}{2}
$$

Analogously, we can derive a chain-weighted series $\Delta_{t, t_{0}}^{\text {rates }}$ that measures the contribution of changes in the rates $i v_{t}^{g}$ to the evolution of $i v_{t} . \Delta_{t, t_{0}}^{\text {shares }}$ and $\Delta_{t, t_{0}}^{\text {rates }}$ add up to $i v_{t}-i v_{t_{0}}$, the actual change in involuntary part-time work from the beginning of the Great Recession until some later date $t$.

Table B2 reports results from the decomposition exercise for various partitions of the labor force by sociodemographic characteristics. First, we observe that changes in employment rates have a negative impact on the recessionary increase in involuntary part-time work. That is, had within-groups part-time rates remained constant, the aggregate rate of involuntary part-time employment would have decreased after December 2007. This effect is mechanical and comes from the negative feedback from unemployment into the involuntary part-time rate noted in Table 2. The second observation is that these contributions are small and largely dominated by changes in within-group rates of involuntary part-time work. The result is true on impact as well as in the ensuing slow recovery. This shows that high rates of involuntary part-time work in the aggregate reflect economic slack within most segments of the labor market. Similar patterns are documented in BML: composition effects explain but a small share of the recessionary increase in part-time employment in general, and involuntary part-time in particular.

\section{B.3 Sensitivity checks}

To demonstrate the robustness of our results, in Table B3 we report the results from the variance decomposition using different definitions of part-time work or sample restrictions. Columns 1a and $1 \mathrm{~b}$ are the baseline. In columns $2 \mathrm{a}$ and $2 \mathrm{~b}$, we define part-time work as less than 30 total usual hours 
Table B3. Variance contributions: Results from sensitivity checks

\begin{tabular}{|c|c|c|c|c|c|c|}
\hline & \multicolumn{2}{|c|}{ Benchmark } & \multicolumn{2}{|c|}{$<30$ hours } & \multicolumn{2}{|c|}{ No multiple jobs } \\
\hline & (1a) & $(1 b)$ & $(2 a)$ & $(2 b)$ & $(3 a)$ & $(3 b)$ \\
\hline & \multicolumn{6}{|c|}{ Involuntary part-time work } \\
\hline Inflows & & & & & & \\
\hline$\beta(F \rightarrow I)$ & 26.5 & 35.5 & 27.1 & 26.9 & 26.5 & 25.8 \\
\hline$\beta(V \rightarrow I)$ & 25.1 & 14.9 & 16.9 & 8.28 & 27.2 & 17.1 \\
\hline$\beta(U \rightarrow I)$ & 3.17 & 1.62 & 7.05 & 6.83 & 7.61 & 5.20 \\
\hline$\beta(N \rightarrow I)$ & 5.30 & 9.66 & 5.57 & 9.72 & 5.04 & 11.6 \\
\hline$\sum_{i \neq I} \beta(i \rightarrow I)$ & 60.1 & 61.6 & 56.7 & 51.7 & 66.4 & 59.8 \\
\hline \multicolumn{7}{|l|}{ Outflows } \\
\hline$\beta(I \rightarrow F)$ & 17.1 & 25.0 & 15.3 & 21.3 & 8.85 & 25.1 \\
\hline$\beta(I \rightarrow V)$ & 18.6 & 2.17 & 19.0 & 12.8 & 18.9 & 9.18 \\
\hline$\beta(I \rightarrow U)$ & 2.72 & 9.42 & 5.84 & 8.50 & 6.88 & 8.81 \\
\hline$\beta(I \rightarrow N)$ & 0.49 & 0.58 & 1.05 & 3.83 & 0.84 & 2.17 \\
\hline$\sum_{j \neq I} \beta(I \rightarrow j)$ & 38.9 & 37.2 & 41.3 & 46.5 & 35.5 & 45.2 \\
\hline$\sum_{(i, j), i \neq j} \beta(i \rightarrow j)$ & 99.0 & 98.8 & 97.9 & 98.2 & 101.8 & 105.1 \\
\hline & \multicolumn{6}{|c|}{ Unemployment } \\
\hline \multicolumn{7}{|l|}{ Inflows } \\
\hline$\beta(F \rightarrow U)$ & 13.0 & 16.9 & 13.2 & 17.4 & 13.2 & 18.0 \\
\hline$\beta(V \rightarrow U)$ & 2.59 & 4.38 & 2.57 & 4.84 & 2.47 & 1.51 \\
\hline$\beta(I \rightarrow U)$ & 5.48 & 8.04 & 5.27 & 7.73 & 3.53 & 8.33 \\
\hline$\beta(N \rightarrow U)$ & 29.3 & 19.0 & 29.1 & 18.9 & 22.7 & 18.1 \\
\hline$\sum_{i \neq U} \beta(i \rightarrow U)$ & 50.3 & 48.3 & 50.1 & 48.9 & 41.9 & 46.0 \\
\hline \multicolumn{7}{|l|}{ Outflows } \\
\hline$\beta(U \rightarrow F)$ & 11.5 & 19.5 & 14.3 & 23.7 & 16.2 & 22.3 \\
\hline$\beta(U \rightarrow V)$ & 4.13 & 4.68 & 2.71 & 2.47 & 0.64 & 0.30 \\
\hline$\beta(U \rightarrow I)$ & 5.22 & 9.90 & 3.80 & 7.47 & 6.86 & 12.9 \\
\hline$\beta(U \rightarrow N)$ & 29.2 & 19.1 & 29.1 & 18.8 & 25.0 & 16.1 \\
\hline$\sum_{j \neq U} \beta(U \rightarrow j)$ & 50.0 & 53.2 & 49.9 & 52.4 & 48.7 & 51.6 \\
\hline$\sum_{(i, j), i \neq j} \beta(i \rightarrow j)$ & 100.4 & 101.6 & 100.0 & 101.3 & 90.6 & 97.6 \\
\hline
\end{tabular}

NOTE: CPS data for the period 1994m01-2015m11. All entries are reported in percent. Columns 1x: baseline definition; all civilians of working-age. Columns 2x: part-time work is defined as less than 30 total usual hours of work per week; all civilians of working-age. Columns $3 \mathrm{x}$ : baseline definition; civilians of working-age who do not hold more than one job. Columns Xa: Data unadjusted for spurious transitions between $V$ and $I$ and between $N$ and $U$. Columns $\mathrm{Xb}$ : Data adjusted for spurious transitions between $V$ and $I$ and between $N$ and $U$. 
of work per week. Columns $3 \mathrm{a}$ and $3 \mathrm{~b}$ revert to the definition of part-time work based on a cutoff of 35 hours, but removes worker who hold more than one job. Finally, in columns 1a, 2a, 3a we do not recode spurious transitions between $V$ and $I$ and also between $N$ and $U$ (therefore we match individuals only across two consecutive periods). Columns $1 b, 2 b, 3 b$ are based on the correction strategy presented in Appendix A.2.

In all instances, we note that the adjusting transitions between $V$ and $I$ lowers the variance contribution of transitions to and from $V$. A similar result holds for spurious transitions between $N$ and $U$ and the variance constribution of $N$ to the unemployment rate. The fit of the dynamic variance decomposition remains very high in all instance, with the exception of columns $3 \mathrm{a}$ and $3 \mathrm{~b}$ : without multiple jobholders, the decomposition explains a significantly lower fraction of variations in the unemployment rate. The results presented in columns $2 b$ and $3 b$ confirm the baseline results reported in Column 1b.

\section{B.4 How subjective is involuntary part-time work?}

A common concern regarding the measurement of involuntary part-time work is that the very notions of "voluntary" and "involuntary" employment appear subjective. As a preamble to the discussion, it should be observed that measurements based on individual survey responses are subject to a specific type of error, in addition to other sources of error. That is, the description of any labor force status is mediated by the interviewee, and therefore exposed to some degree of subjectivity. This obviously affects the measurement of involuntary part-time work, but not necessarily more than other labor market concepts. The distinction between being "unemployed" and "out of the labor force", for instance, is based on self-reported job-search behavior, which may range from almost nonexistent to very active (see e.g. Jones and Riddell, 1999). The distinction between employment and non-employment is perhaps not more firmly established. For example, an individual who is temporarily helping a family member while searching for a job may consider her/himself unemployed and be classified as such, even if the family member gives her a salary in exchange for the help provided. ${ }^{30}$ Thus, without pushing the argument to the extreme, one can recognize that subjectivity affects virtually any work based on labor force survey data.

Another observation is that our focus is on the cyclical variation of involuntary part-time work, rather than the level, which attenuates some of these measurement concerns. For instance, in Figure A2, we find no evidence of cyclicality in the amount of spurious $V \rightarrow I$ and $I \rightarrow V$ transitions. This could indicate that recessions have no significant effect on whether part-time workers describe their current employment status as voluntary or not.

All said and done, one cannot reach a definite conclusion on whether survey respondents have a tendency to over or under-report involuntary part-time work. We can however check the consistency of their answers. The fact that involuntary part-time work is attributed to either "slack demand condition" or "inability to find a full-time job" (Section 2) is informative for that purpose. We expect those from the first category to be predominantly employed workers who stay at the same company

\footnotetext{
${ }^{30}$ Sociologists and historians have a long tradition of analyzing labor market status as "social constructs". For instance, historically, the use of unemployment as a basis of category for statistics was only possible after the emergence of a salaried workforce which helped materialize the difference between idleness and joblessness.
} 
and wait until economic conditions improve. In the second category, we expect to see mostly unemployed workers who temporarily accept a part-time job as a route towards full-time employment. We confront these predictions with the data below.

\section{Findings from longer labor market trajectories}

To gain insights into the meaning of "slack work" (SW) / "could not find a full-time job" (CF), we first analyze the trajectories of those who remain in involuntary part-time work for four consecutive months: that is, $I \rightarrow I \rightarrow I \rightarrow I$. Panel a. of Figure B1 describes these employment spells: the number in square brackets is the fraction of spells the initial condition of which is $\mathrm{SW}$ or $\mathrm{CF}$, and the numbers in curved brackets give the conditional distribution of the subsequent states. Over the whole sample period, the stated reason for involuntary part-time work in the first month is evenly split between "slack work" and "could not find full-time work": 50.2\% vs. 49.8\%. We then observe a fair amount of persistence in subsequent months (green trajectories). ${ }^{31}$ For instance, $61.8 \%$ of spells beginning with slack work report the same reason for involuntary part-time work in months two, three and four. Also, we see that only around $10 \%$ of these spells consistently report another reason than the initial one in months two to four (blue trajectories, either $S W_{1} \rightarrow C F_{2} \rightarrow C F_{3} \rightarrow C F_{4}$ or $C F_{1} \rightarrow S W_{2} \rightarrow S W_{3} \rightarrow S W_{4}$ ). This number is reassuring, but is counterbalanced by the fact that we also observe some erratic trajectories (red trajectories; for example $S W_{1} \rightarrow C F_{2} \rightarrow C F_{3} \rightarrow S W_{4}$ ) which account for about $20 \%$ of trajectories. In sum, the answers "slack work" (SW) / "could not find a full-time job" (CF) should be treated with caution in at least one third of all cases.

We continue the analysis of the stated reasons "slack work" and "could not find a full-time job" by examining how they relate to the labor market status before a spell of involuntary part-time work. Panel b. of Figure B1 describe spells $F \rightarrow F \rightarrow I \rightarrow I$ (two months in full-time work, followed by two months of involuntary part-time work) and $U \rightarrow U \rightarrow I \rightarrow I$ (two months in unemployment, followed by two months of involuntary part-time work). ${ }^{32}$ For the majority of spells preceded by full-time employment, "slack work" becomes the dominant stated reason over the next two months (74.1\% in month three, out of which $87.3 \%$ report "slack work" in month four). Conversely, spells that are preceded by unemployment often involve "could not find a full-time job" as the main reason in month three $(61.7 \%)$, which persists in month four in $76.1 \%$ of cases. The fact that a non-negligible proportion of unemployed workers who take on a part-time job is recorded as $S W$ in month three is perhaps explained by the fact that "slack demand conditions" is a broader phenomenon. For example, the lack of full-time job sometimes originates from slack demand conditions. All in all, the stated reasons "slack work" and "could not find a full-time job" appear reasonably linked to actual labor market trajectories.

\footnotetext{
${ }^{31}$ Notice that there is no reason to expect a strong persistence in these answers. For instance, suppose that a full-time worker is relocated to a part-time job due to poor demand conditions, which she describes as such in the first month of interview $\left(S W_{1}\right)$. The worker may start looking for a job elsewhere and, if she fails repeatedly to find such a job, she may report that the lack of full-time jobs is her main reason for working part-time involuntarily $\left(C F_{2}, C F_{3}\right.$ and/or $\left.C F_{4}\right)$.

${ }^{32}$ To minimize measurement error, we look at spells in which the labor market status (either $F, U$ or $I$ ) is consistent across two consecutive months.
} 


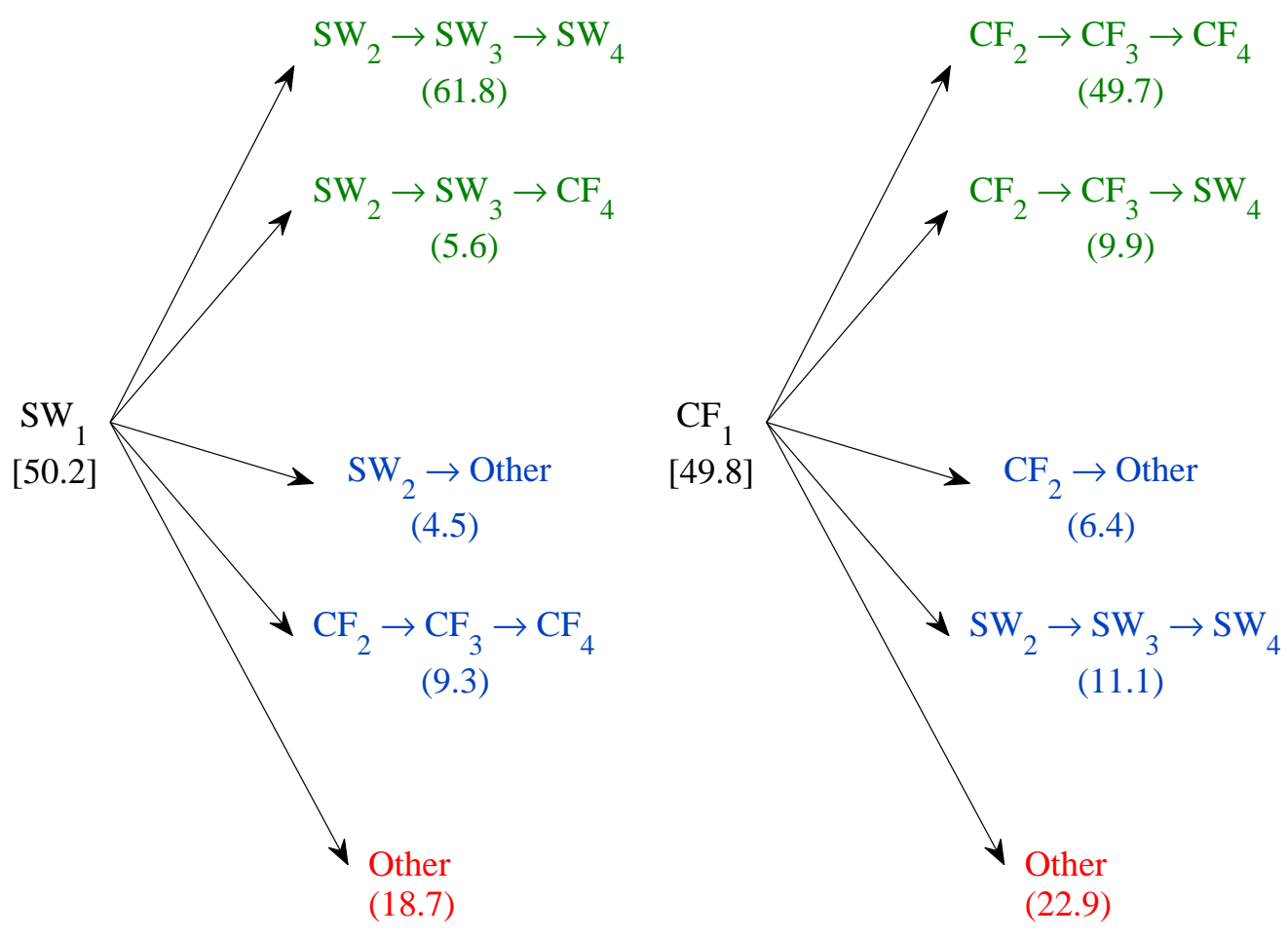

(a) $I \rightarrow I \rightarrow I \rightarrow I$ spells starting with "Slack work" (left) or "Could not find a full-time job" (right)
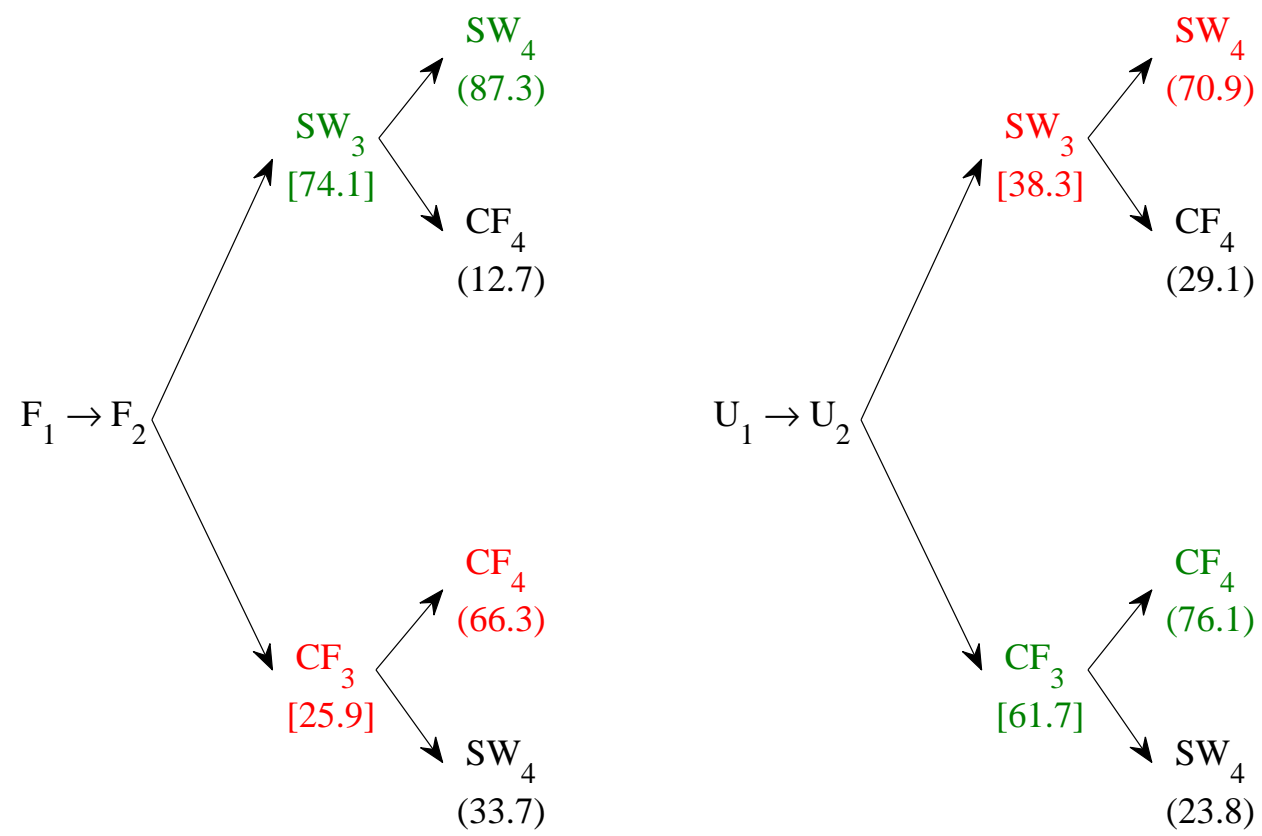

(b) $F \rightarrow F \rightarrow I \rightarrow I$ spells (left) and $U \rightarrow U \rightarrow I \rightarrow I$ spells (right)

Figure B1. "Slack work" (SW) vs. "Could not find a full-time job" (CF): Some examples

Pooled CPS data for the period 1994m01-2015m05. The time- $t$ subscript on labor market states $S W_{t}$, $C F_{t}, F_{t}, U_{t}$ indicates the month of interview. 


\section{B.5 A look at earnings and hours of work}

A detailed investigation of the wage penalty associated with involuntary part-time work is beyond the scope of the paper. There exists a vast literature on the part-time wage penalty, and we have checked that our parameterization of earnings and hours in Subsection 4.2 is consistent with findings from this literature. ${ }^{33}$ Instead, in this subsection, we report and comment on some results based on our CPS data that are very well-aligned with the findings reported in the literature on the part-time wage penalty.

We pool data from the Outgoing Rotation Group of the CPS for the period 2001m12-2007m11 (that is, between the two recessions covered by our dataset). Our variable of interest is (the $\log$ of) hourly earnings (including usual amounts of overtime, tips, commissions, and bonuses) expressed in 2012 U.S. \$, and trimmed at the bottom and top 1 percent of the distribution. We run OLS regressions separately for male and female workers, and consider three nested specifications. The first one includes only a dummy for part-time work (that is, it measures the raw difference in hourly earnings across the two job categories). The second one adds a set of worker-level characteristics (a quartic in age, education dummies and marital dummies). The third specification adds a set of job-level characteristics (occupation and industry dummies). ${ }^{34}$ Finally, for illustrative purposes, we run these regressions separately to estimate the penalty of overall part-time work $(V+I)$ and the penalty of involuntary part-time work $(I)$ only. The results are presented in Panel a. of Table B4.

Table B4. Earnings and hours in overall part-time and involuntary part-time work

\begin{tabular}{lcccccccc}
\hline a. Earnings gap & \multicolumn{3}{c}{ Male workers } & & \multicolumn{3}{c}{ Female workers } \\
\cline { 2 - 4 } \cline { 6 - 8 } Overall part-time $(V+I)$ & -0.608 & -0.288 & -0.201 & & -0.323 & -0.179 & -0.112 \\
& $(0.003)$ & $(0.003)$ & $(0.003)$ & & $(0.002)$ & $(0.002)$ & $(0.002)$ \\
Involuntary part-time $(I)$ & -0.519 & -0.274 & -0.185 & & -0.397 & -0.230 & -0.134 \\
& $(0.006)$ & $(0.006)$ & $(0.005)$ & & $(0.004)$ & $(0.004)$ & $(0.004)$ \\
Worker-level controls & $\mathrm{N}$ & $\mathrm{Y}$ & $\mathrm{Y}$ & & $\mathrm{N}$ & $\mathrm{Y}$ & $\mathrm{Y}$ \\
Job-level controls & $\mathrm{N}$ & $\mathrm{N}$ & $\mathrm{Y}$ & & $\mathrm{N}$ & $\mathrm{N}$ & $\mathrm{Y}$ \\
& & & & & & & \\
\hline
\end{tabular}

\section{b. Hours}

\begin{tabular}{lccc}
\cline { 3 - 4 } & \multirow{2}{*}{ Full-time } & \multicolumn{2}{c}{ Part-time } \\
\cline { 3 - 4 } Mean & 43.7 & Overall & Involuntary \\
Median & 40.0 & 21.6 & 24.0 \\
& & 20.0 & 25.0
\end{tabular}

\begin{tabular}{ccc}
\hline \multirow{2}{*}{ Full-time } & \multicolumn{2}{c}{ Part-time } \\
\cline { 2 - 3 } 41.4 & Overall & Involuntary \\
40.0 & 21.4 & 23.6 \\
& 20.0 & 25.0
\end{tabular}

NoTE: CPS data, outgoing rotation group for the period 2001m12-2007m11. Panel A: Each entry is from a separate OLS regression of the log hourly earnings against a dummy for overall part-time work (first row) or involuntary parttime work (second row), and further controls at the worker-level (N/Y) and job-level (N/Y). Standard errors in parentheses. Panel B: Average and median hours worked in full-time, in overall part-time and in involuntary part-time jobs.

\footnotetext{
${ }^{33}$ The literature is too large to be surveyed here. One representative example of this body of research is the study by Hirsch (2005): it is based on CPS data and the author addresses the issue of unobserved heterogeneity by using the panel structure of the CPS and transition across full-time and part-time jobs. Unobserved heterogeneity is a key concern for estimating the part-time wage penalty, which in turn raises questions about the appropriate use of instrumental variables; see the analysis of Aaronson and French (2004) based on administrative data.

${ }^{34}$ We do not attach any causal interpretation to these OLS regressions, and we adopt standard specifications although they raise valid concerns of endogeneity bias.
} 
As can be observed in the first column, there is a significant and large earnings penalty in the raw data (-60.8\% in $V+I,-51.9 \%$ in $I$ for men; $-32.3 \%$ in $V+I,-39.7 \%$ in $I$ for women). We note that the penalty is higher for men in overall part-time work compared to involuntary work, while the pattern is reversed for women. In line with the existing literature, we also find that individual controls account for a large share of the observed differential, and that including job characteristics further reduces the difference in earnings. After accounting for (observed) individual and job characteristics, the parttime penalty is between $-20.0 \%$ and $-18.5 \%$ for men, and between $-13.4 \%$ and $-11.2 \%$ for women. The finding that the part-time penalty is larger for male than for female workers is again consistent with the literature. Finally, the magnitude of the penalty is very similar to estimates reported in the literature, and which in some cases are based on specifications that are arguably more immune to endogeneity biases (see e.g. Hirsch, 2005). In the calibrated model, we take the part-time wage penalty to be $-15 \%$, a figure well within the range of the estimates presented in Table B4.

Panel b. of Table B4 reports average and median (usual) hours worked in full-time, in overall part-time and in involuntary part-time jobs. The gap in hours worked is close to 50 percent when we compare full-time jobs with overall part-time jobs, and is reduced when we only consider involuntary part-time jobs. In a previous version of the model, we calibrated $h_{P}$ and $h_{F}$ under the assumption that the difference in hours is exactly 50 percent. The results were similar to those obtained under the current calibration, which selects the parameters to reproduce median hours worked in full-time and in involuntary part-time work. 


\section{Model appendix}

This appendix complements Section 4 by providing details on the model (Bellman equations and policy functions), on the calibrated parameters, computations and by reporting results for the numerical experiments using different preference parameters.

\section{C.1 Bellman equations}

The decision problem of the worker can be formulated in recursive form. Hereafter, $W_{i}$ denote the value of being employed in a job $i \in\{P, F\} ; U_{1}$ is the value of being unemployed and collecting unemployment benefits; $U_{0}$ is the value of being unemployed and collecting social assistance benefits.

Beginning with the value functions in employment, these solve:

$$
\begin{array}{r}
W_{i}(a)=\max _{a^{\prime}, h}\left\{\frac{\left(c\left(\bar{h}-h_{i}-h\right)^{\eta}\right)^{1-\sigma}-1}{1-\sigma}+\beta\left(\lambda h \left(\phi_{P} \max \left\{\bar{W}_{i}\left(a^{\prime}\right), W_{P}\left(a^{\prime}\right)\right\}\right.\right.\right. \\
\left.\left.\left.+\left(1-\phi_{P}\right) \max \left\{\bar{W}_{i}\left(a^{\prime}\right), W_{F}\left(a^{\prime}\right)\right\}\right)+(1-\lambda h) \bar{W}_{i}\left(a^{\prime}\right)\right)\right\}
\end{array}
$$

subject to

$$
\begin{aligned}
c+a^{\prime} & \leq(1+r) a+w_{i} \\
a^{\prime} & \geq 0 \\
h & \in\left[0, \bar{h}-h_{i}\right]
\end{aligned}
$$

where $\bar{W}_{i}(a) \equiv \pi_{i, F} \max \left\{W_{F}(a), U_{0}(a)\right\}+\pi_{i, P} \max \left\{W_{P}(a), U_{0}(a)\right\}+\pi_{i, U} U_{1}(a)$ is the value of being employed in a job $i \in\{P, F\}$ by the end of the model period.

In unemployment, we index the value functions by $j \in\{0,1\}$ to write the Bellman equations as:

$$
\begin{array}{r}
U_{j}(a)=\max _{a^{\prime}, h}\left\{\frac{\left(c(\bar{h}-h)^{\eta}\right)^{1-\sigma}-1}{1-\sigma}+\beta\left(\lambda h \left(\phi_{P} \max \left\{\bar{U}_{j}\left(a^{\prime}\right), W_{P}\left(a^{\prime}\right)\right\}\right.\right.\right. \\
\left.\left.\left.+\left(1-\phi_{P}\right) \max \left\{\bar{U}_{j}\left(a^{\prime}\right), W_{F}\left(a^{\prime}\right)\right\}\right)+(1-\lambda h) \bar{U}_{j}\left(a^{\prime}\right)\right)\right\}
\end{array}
$$

subject to

$$
\begin{aligned}
c+a^{\prime} & \leq(1+r) a+\theta_{j} \\
a^{\prime} & \geq 0 \\
h & \in[0, \bar{h}]
\end{aligned}
$$

with $\bar{U}_{1}(a) \equiv\left(1-\phi_{U}\right) U_{1}(a)+\phi_{U} U_{0}(a)$ and $\bar{U}_{0}(a) \equiv U_{0}(a)$ giving the end-of-period value functions of the worker during unemployment. 


\section{C.2 Policy functions}

The above set of Bellman equations delivers three types of decisions. First, there are decision rules for asset holdings $\widetilde{a}^{F}(a), \widetilde{a}^{P}(a), \widetilde{a}_{1}^{U}(a), \widetilde{a}_{0}^{U}(a)$ associated with equations (15) and (16), respectively. Second, there are decision rules for search effort $\widetilde{h}^{F}(a), \widetilde{h}^{P}(a), \widetilde{h}_{1}^{U}(a), \widetilde{h}_{0}^{U}(a)$ associated with equations (15) and (16), respectively. Finally, there are work decisions associated with the comparison of value functions in employment and unemployment. That is,

$$
\varepsilon_{i, j}(a)=\mathbb{1}\left\{W_{i}(a)>U_{j}(a)\right\}
$$

for all $i \in\{P, F\}$ and $j \in\{0,1\}$, as well as

$$
\varepsilon_{F, P}(a)=\mathbb{1}\left\{W_{F}(a)>W_{P}(a)\right\}
$$

$(\mathbb{1}\{$.$\} is the indicator function). Notice that in (17) and (18), uncertainty about labor market status$ if the worker decides not to accept the job opportunity is resolved. That is, we assume that job destruction and exhaustion of benefits occur before the end of the model period. This is consistent with the formulation of equations (15) and (16) since, from the perspective of the beginning-of-period, the worker is uncertain about her outside option if she receives a job offer by the end of the period.

\section{C.3 Parameter values}

Tables C1a and C1a summarizes the calibration. Table C1a reports parameter values which remain unchanged across calibrations. Table $\mathrm{C} 1 \mathrm{~b}$ shows the parameter values obtained under various specifications of the utility function. The lower coefficient of risk aversion is $\sigma=1.0$ (utility is logarithmic in consumption and additively separable). For symmetry around the benchmark, the higher coefficient of risk aversion is $\sigma=3.0$. The model is calibrated using $\eta \in\{0.25,0.50,0.75\}$.

Table C1a. Parameters values: Parameters set externally

$\begin{array}{lccl}\text { Interest rate } & r & 0.003 & 3.5 \text { percent annual interest rate } \\ \text { Time endowment } & \bar{h} & 1.0 & \text { Normalization } \\ \text { Part-time hours of work } & h_{P} & 0.245 & \text { Workweek length of } 24 \text { hours } \\ \text { Full-time hours of work } & h_{F} & 0.429 & \text { Workweek length of } 42 \text { hours } \\ \text { Part-time earnings } & w_{P} & 0.485 & \text { Part-time wage penalty of } 15 \text { percent } \\ \text { Full-time earnings } & w_{F} & 1.00 & \text { Normalization } \\ \text { Social assistance benefits } & \theta_{0} & 0.05 & \text { OECD (2007) } \\ \text { Unemployment benefits } & \theta_{1} & 0.45 & \text { OECD (2007) } \\ \text { Probability of exhausting benefits } & \phi_{U} & 0.167 & \text { Benefit period of 26 weeks }\end{array}$


Table C1b. Parameter values: Parameters set internally

\begin{tabular}{cccccccccc} 
& \multicolumn{3}{c}{$\sigma=1.0$} & \multicolumn{4}{c}{$\sigma=2.0$} & \multicolumn{3}{c}{$\sigma=3.0$} \\
$\eta$ & 0.25 & 0.50 & 0.75 & 0.25 & 0.50 & 0.75 & 0.25 & 0.50 & 0.75 \\
$\beta$ & 0.9965 & 0.9963 & 0.9959 & 0.9907 & 0.9902 & 0.9896 & 0.9781 & 0.9712 & 0.9708 \\
$\lambda$ & 0.3912 & 0.4357 & 0.4689 & 0.3942 & 0.4537 & 0.5110 & 0.4095 & 0.4578 & 0.5361 \\
$\phi_{P}$ & 0.1801 & 0.1741 & 0.1725 & 0.1837 & 0.1792 & 0.1775 & 0.1847 & 0.1825 & 0.1781
\end{tabular}

Note: $\sigma$ : Coefficient of relative risk aversion. $\eta$ : relative value of leisure. $\beta$ : subjective discount factor. $\lambda$ : jobfinding parameter. $\phi_{P}$ : fraction of part-time job offers.

\section{C.4 Computation of welfare effects}

This appendix presents the calculation of the welfare effects reported in Sections 4.3 and 4.4.

\section{Experiment I}

Experiment I (Section 4.3) relies on the comparison of cross-sectional utility across cohorts of workers with identical preferences. These workers are homogeneous in assets at the time of the displacement shock, and since we follow workers over a short period of time (our focus is on the first two quarters after displacement), they remain very homogeneous within each cohort. Therefore we treat each cohort as a representative worker.

Consider for instance the comparison of cohorts 1 and 2, $t$ periods after the shock. We measure cross-sectional utility, $U_{k, t}$, in each cohort $k \in\{1,2\}$. Let $C_{k, t}$ and $H_{k, t}$ denote consumption and leisure, respectively, of the representative worker. The treatment effect $\vartheta_{1,2}^{t}$ we report satisfies:

$$
U\left(\left(1+\vartheta_{1,2}^{t}\right) C_{1, t}, H_{1, t}\right)=U\left(C_{2, t}, H_{2, t}\right)
$$

For the class of utility function considered, this gives:

$$
1+\vartheta_{1,2}^{t}=\left[\frac{U_{2, t}+\frac{1}{1-\sigma}}{U_{1, t}+\frac{1}{1-\sigma}}\right]^{\frac{1}{1-\sigma}}
$$

Next, consider cohorts 2 and 3 (for instance, to compute the effects of moving from column 2 to 3 in Table 8). Since $\vartheta_{2,3}^{t}$ satisfies an equation similar to (20), we can show that:

$$
\left(1+\vartheta_{1,2}^{t}\right)\left(1+\vartheta_{2,3}^{t}\right)=1+\vartheta_{1,3}^{t}
$$

$\vartheta_{1,3}^{t} \approx \vartheta_{1,2}^{t}+\vartheta_{2,3}^{t}$ is valid as a first-order approximation of this equation. Using this result, we compute the cumulative welfare effects in Table 8 as:

$$
\vartheta_{1,4}^{t}=\sum_{k=1}^{3} \vartheta_{k, k+1}^{t}
$$




\section{Experiment II}

Experiment II (Section 4.4) relies on the comparison of lifetime values in full-time employment, when the cyclical risk of involuntary part-time work changes. Let, for instance, $W_{F}(a, z)\left(\right.$ resp. $\widetilde{W}_{F}(a, z)$ ) denote the value of full-time work with asset $a$ when the aggregate state of the economy is $z$ and $\varepsilon_{F, P}=0$ (resp. $\varepsilon_{F, P}>0$ ). The welfare implications of $\varepsilon_{F, P}>0$ are measured as:

$$
1+\vartheta(a, z)=\left[\frac{\widetilde{W}_{F}(a, z)+\frac{1}{1-\beta} \frac{1}{1-\sigma}}{W_{F}(a, z)+\frac{1}{1-\beta} \frac{1}{1-\sigma}}\right]^{\frac{1}{1-\sigma}}
$$

The Markov process for $z$ is symmetric, which makes the worker spend half of her time in $z=z_{b}$ and the other half in $z=z_{g}$. Thus, we let

$$
\vartheta(a) \equiv \vartheta\left(a, z_{b}\right)+\vartheta\left(a, z_{g}\right)
$$

measure the welfare effect at a given asset level. Finally, in Table 9, we report the range of values $\vartheta(a)$ computed over the support for asset holdings. This avoids aggregating the values $\vartheta(a)$ using a given distribution over asset holdings, and it gives a good approximation of the average welfare effect since the range of computed values is quite narrow.

\section{C.5 Robustness checks}

Table C2 reports robustness checks for the experiments presented in Table 8. The coefficient of relative risk aversion is $\sigma=2.0$ and we report results for $\eta=0.25$ and $\eta=0.75$. To facilitate comparisons, Panels 1.b and 2.b reproduce the results from Table 8.

Tables C3 and C4 reports robustness checks for the experiments presented in Table 9 using, respectively, a low $(\sigma=1.0)$ and high $(\sigma=3.0)$ coefficient of relative risk aversion. 


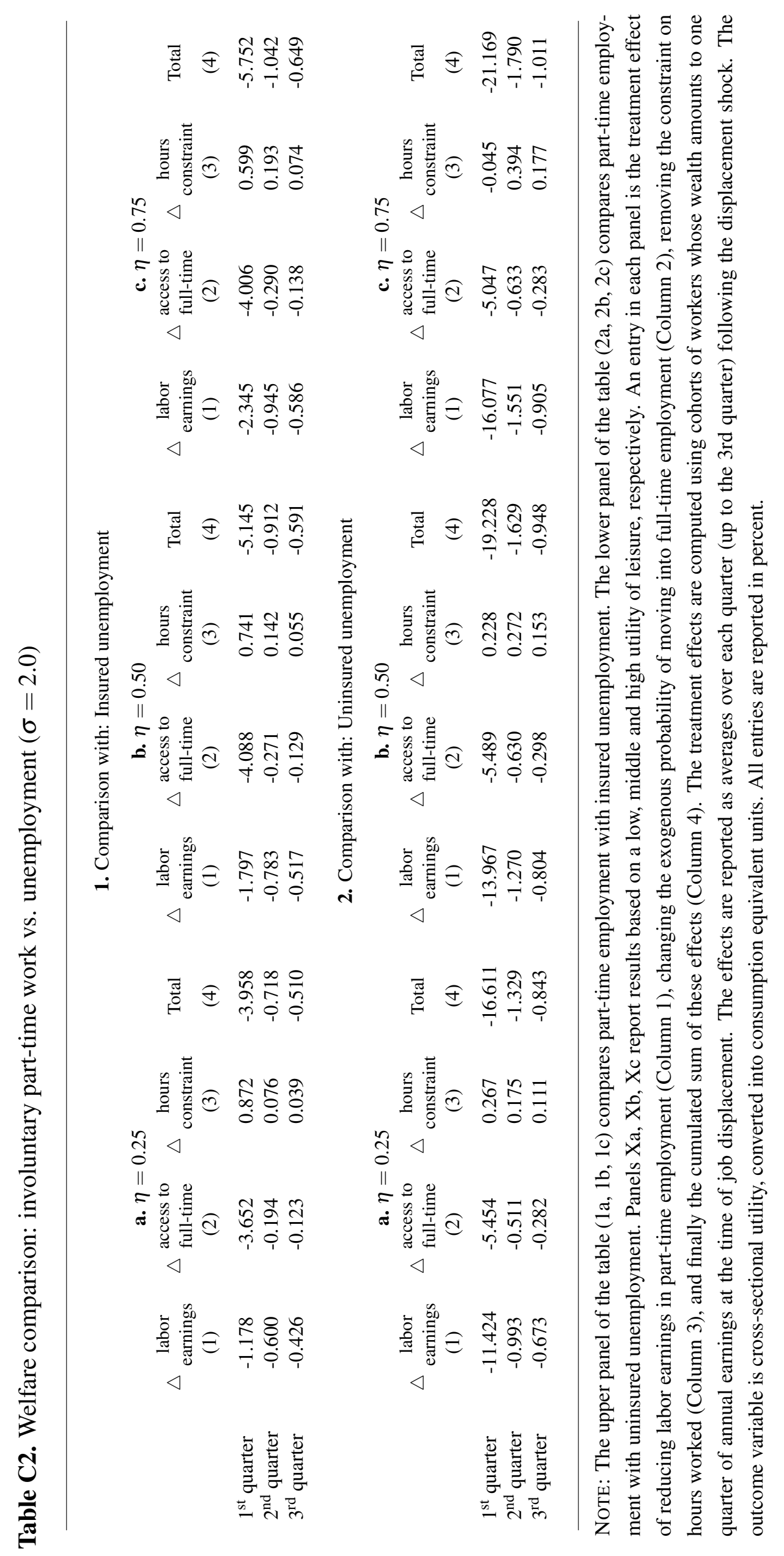


Table C3. Welfare effects of an increase in the cyclical risk of involuntary part-time work $(\sigma=1)$

\begin{tabular}{|c|c|c|c|c|c|c|}
\hline & \multicolumn{6}{|c|}{ 1. Deviations around $\pi_{F, P}=0.01$} \\
\hline & \multicolumn{2}{|c|}{ a. $\eta=0.25$} & \multicolumn{2}{|c|}{ b. $\eta=0.50$} & \multicolumn{2}{|c|}{ c. $\eta=0.75$} \\
\hline & $\begin{array}{c}\varepsilon_{F, P}=0.20 \\
(1)\end{array}$ & $\begin{array}{c}\varepsilon_{F, P}=0.40 \\
\text { (2) }\end{array}$ & $\begin{array}{c}\varepsilon_{F, P}=0.20 \\
(1)\end{array}$ & $\begin{array}{c}\varepsilon_{F, P}=0.40 \\
(2)\end{array}$ & $\begin{array}{c}\varepsilon_{F, P}=0.20 \\
\quad(1)\end{array}$ & $\begin{array}{c}\varepsilon_{F, P}=0.40 \\
(2)\end{array}$ \\
\hline$\varepsilon_{P, F}=0.05$ & {$[-0.010,-0.010]$} & {$[-0.016,-0.016]$} & {$[-0.015,-0.014]$} & {$[-0.023,-0.022]$} & {$[-0.018,-0.017]$} & {$[-0.027,-0.026]$} \\
\hline$\varepsilon_{P, F}=0.10$ & {$[-0.029,-0.029]$} & {$[-0.048,-0.046]$} & {$[-0.041,-0.040]$} & {$[-0.067,-0.065]$} & {$[-0.054,-0.052]$} & {$[-0.085,-0.082]$} \\
\hline \multirow[t]{4}{*}{$\varepsilon_{P, F}=0.15$} & {$[-0.053,-0.051]$} & {$[-0.084,-0.081]$} & {$[-0.073,-0.072]$} & {$[-0.117,-0.115]$} & {$[-0.099,-0.097]$} & {$[-0.152,-0.149]$} \\
\hline & \multicolumn{6}{|c|}{ 2. Deviations around $\pi_{F, P}=0.02$} \\
\hline & \multicolumn{2}{|c|}{ a. $\eta=0.25$} & \multicolumn{2}{|c|}{ b. $\eta=0.50$} & \multicolumn{2}{|c|}{ c. $\eta=0.75$} \\
\hline & $\begin{array}{c}\varepsilon_{F, P}=0.20 \\
\text { (1) }\end{array}$ & $\begin{array}{c}\varepsilon_{F, P}=0.40 \\
(2)\end{array}$ & $\begin{array}{c}\varepsilon_{F, P}=0.20 \\
\text { (1) }\end{array}$ & $\begin{array}{c}\varepsilon_{F, P}=0.40 \\
\text { (2) }\end{array}$ & $\begin{array}{c}\varepsilon_{F, P}=0.20 \\
\text { (1) }\end{array}$ & $\begin{array}{c}\varepsilon_{F, P}=0.40 \\
\text { (2) }\end{array}$ \\
\hline$\varepsilon_{P, F}=0.05$ & {$[-0.014,-0.014]$} & {$[-0.010,-0.010]$} & {$[-0.020,-0.020]$} & {$[-0.016,-0.015]$} & {$[-0.023,-0.022]$} & {$[-0.017,-0.016]$} \\
\hline$\varepsilon_{P, F}=0.10$ & {$[-0.048,-0.046]$} & {$[-0.067,-0.065]$} & {$[-0.067,-0.066]$} & {$[-0.095,-0.093]$} & {$[-0.086,-0.083]$} & {$[-0.118,-0.114]$} \\
\hline$\varepsilon_{P, F}=0.15$ & {$[-0.088,-0.086]$} & {$[-0.131,-0.127]$} & {$[-0.124,-0.123]$} & {$[-0.184,-0.181]$} & {$[-0.165,-0.161]$} & {$[-0.235,-0.228]$} \\
\hline
\end{tabular}

NOTE: The table reports the effects of an increase in the cyclical risk of involuntary part-time employment. The upper panel of the table $(1 \mathrm{a}, 1 \mathrm{~b}, 1 \mathrm{c})$ shows the effects of deviations around the monthy transition probability $\pi_{F, P}=0.01$. The lower panel of the table $(2 \mathrm{a}, 2 \mathrm{~b}, 2 \mathrm{c})$ shows the effects of deviations around the monthly transition probability $\pi_{F, P}=0.02$. Panels Xa, Xb, Xc report results based on a low, middle and high utility of leisure, respectively. An entry in each panel shows the range of welfare effects computed at different levels of asset holdings. The welfare effects measure the percentage change in lifetime consumption of moving from an environment with $\varepsilon_{P, F}=\varepsilon_{F, P}=0$ to an environment with $\varepsilon_{P, F}>0$ and $\varepsilon_{P, F}>0$. All entries are reported in percent. 
Table C4. Welfare effects of an increase in the cyclical risk of involuntary part-time work $(\sigma=3)$

\begin{tabular}{|c|c|c|c|c|c|c|}
\hline & \multicolumn{6}{|c|}{ 1. Deviations around $\pi_{F, P}=0.01$} \\
\hline & \multicolumn{2}{|c|}{ a. $\eta=0.25$} & \multicolumn{2}{|c|}{ b. $\eta=0.50$} & \multicolumn{2}{|c|}{ c. $\eta=0.75$} \\
\hline & $\begin{array}{c}\varepsilon_{F, P}=0.20 \\
\quad(1)\end{array}$ & $\begin{array}{c}\varepsilon_{F, P}=0.40 \\
(2)\end{array}$ & $\begin{array}{c}\varepsilon_{F, P}=0.20 \\
\quad(1)\end{array}$ & $\begin{array}{c}\varepsilon_{F, P}=0.40 \\
(2)\end{array}$ & $\begin{array}{c}\varepsilon_{F, P}=0.20 \\
\quad(1)\end{array}$ & $\begin{array}{c}\varepsilon_{F, P}=0.40 \\
(2)\end{array}$ \\
\hline$\varepsilon_{P, F}=0.05$ & {$[-0.014,-0.014]$} & {$[-0.023,-0.017]$} & {$[-0.020,-0.017]$} & {$[-0.031,-0.025]$} & {$[-0.024,-0.020]$} & {$[-0.037,-0.025]$} \\
\hline$\varepsilon_{P, F}=0.10$ & {$[-0.043,-0.041]$} & {$[-0.070,-0.065]$} & {$[-0.062,-0.057]$} & {$[-0.096,-0.083]$} & {$[-0.078,-0.072]$} & {$[-0.119,-0.102]$} \\
\hline \multirow{4}{*}{$\varepsilon_{P, F}=0.15$} & {$[-0.079,-0.074]$} & {$[-0.124,-0.116]$} & {$[-0.115,-0.108]$} & {$[-0.174,-0.159]$} & {$[-0.150,-0.139]$} & {$[-0.220,-0.198]$} \\
\hline & \multicolumn{6}{|c|}{ 2. Deviations around $\pi_{F, P}=0.02$} \\
\hline & \multicolumn{2}{|c|}{ a. $\eta=0.25$} & \multicolumn{2}{|c|}{ b. $\eta=0.50$} & \multicolumn{2}{|c|}{ c. $\eta=0.75$} \\
\hline & $\begin{array}{l}\varepsilon_{F, P}=0.20 \\
\quad(1)\end{array}$ & $\begin{array}{c}\varepsilon_{F, P}=0.40 \\
(2)\end{array}$ & $\begin{array}{l}\varepsilon_{F, P}=0.20 \\
\quad(1)\end{array}$ & $\begin{array}{c}\varepsilon_{F, P}=0.40 \\
(2)\end{array}$ & $\begin{array}{l}\varepsilon_{F, P}=0.20 \\
\quad(1)\end{array}$ & $\begin{array}{c}\varepsilon_{F, P}=0.40 \\
(2)\end{array}$ \\
\hline$\varepsilon_{P, F}=0.05$ & {$[-0.020,-0.016]$} & {$[-0.024,-0.011]$} & {$[-0.026,-0.022]$} & {$[-0.026,-0.002]$} & {$[-0.030,-0.022]$} & {$[-0.030,-0.000]$} \\
\hline$\varepsilon_{P, F}=0.10$ & {$[-0.067,-0.063]$} & {$[-0.099,-0.079]$} & {$[-0.092,-0.086]$} & {$[-0.130,-0.101]$} & {$[-0.113,-0.097]$} & {$[-0.156,-0.119]$} \\
\hline$\varepsilon_{P, F}=0.15$ & {$[-0.126,-0.119]$} & {$[-0.184,-0.167]$} & {$[-0.176,-0.159]$} & {$[-0.254,-0.206]$} & {$[-0.221,-0.199]$} & {$[-0.310,-0.272]$} \\
\hline \multicolumn{7}{|c|}{$\begin{array}{l}\text { NOTE: The table reports the effects of an increase in the cyclical risk of involuntary part-time employment. The up- } \\
\text { per panel of the table }(1 \mathrm{a}, 1 \mathrm{~b}, 1 \mathrm{c}) \text { shows the effects of deviations around the monthy transition probability } \pi_{F, P}=0.01 \text {. } \\
\text { The lower panel of the table }(2 \mathrm{a}, 2 \mathrm{~b}, 2 \mathrm{c}) \text { shows the effects of deviations around the monthly transition probability } \\
\pi_{F, P}=0.02 \text {. Panels } \mathrm{Xa}, \mathrm{Xb}, \mathrm{Xc} \text { report results based on a low, middle and high utility of leisure, respectively. An en- } \\
\text { try in each panel shows the range of welfare effects computed at different levels of asset holdings. The welfare effects } \\
\text { measure the percentage change in lifetime consumption of moving from an environment with } \varepsilon_{P, F}=\varepsilon_{F, P}=0 \text { to an } \\
\text { environment with } \varepsilon_{P, F}>0 \text { and } \varepsilon_{P, F}>0 \text {. All entries are reported in percent. }\end{array}$} \\
\hline
\end{tabular}




\section{Additional background and international evidence [Not intended for publication]}

\section{D.1 Public insurance in the U.S.}

In the introduction we mentioned that labor income losses associated with spells of involuntary parttime were not covered by any specific public insurance scheme. While we believe that in practice that statement is still generically true for the majority of workers in our sample, it needs some important qualifications. In fact, other public programs in the U.S. provide some degree of income insurance to certain groups of workers. In the next paragraphs we describe succintly three public programs (as many as we are aware of and that are likely to benefit involuntary part-time workers). Our main provisional conclusion is that these programs are unlikely to cover the majority of workers undergoing spells of involuntary part-time work. This conclusion combines results from our empirical analysis and academic research on the scope, eligibility and take-up of these programs.

The most prominent program is the Earned Income Tax Credit (EITC). This in-work benefit program provides income support to individuals based on their income and their family's income and structure. In particular, eligibility is determined by the presence of qualifying children in the household, positive labor earnings below a certain threshold (for example, 50,000 dollars per year for a family with two children) and a maximum threshold of nonlabor income (which is lower than the labor income threshold). Based on the CPS data alone it is not possible to determine exactly which fraction of involuntary part-time workers are eligible to an EITC, much less the amount of their entitlement. However, according to Nichols and Rothstein (2015), single parents with no children are unlikely to receive any or very small amounts, and families without children also benefit much less from the program. Since information on children and civil status is available on the MORG extracts, we can compute the share of involuntary part-time workers accounted by these sub-populations. We find that on average over the last ten years of data the share of involuntary part-time workers who are single and unmarried is $25 \%$ and of damilies with no children $15 \%$. This implies that the share of ineligible workers has a lower bound at $40 \%$ A perhaps less well-known aspect of the EITC is that, due to the way it is implemented (payments are only made in the spring of following the tax year), it is likely to provide a weak consumption smoothing insurance for poor families with no assets.

A perhaps less prominent program that may provide income support to workers in involuntary part-time are state-run partial unemployment insurance systems. Unfortunately, we cannot offer a complete characterization of their scope, eligibility conditions and benefits in the context of the U.S. economy at large, as available information on this matter (even on the internet) is limited. Le Barbanchon (2015) provides a detailed account of these schemes in the four states covered by his sample (Idaho, Louisiana, Missouri and New Mexico). In these states workers claiming unemployment insurance are eligible for partial unemployment benefits. The eligibility condition vary across states, but in general claimants cannot earn over a maximum amount of labor income per week, which is usually set to a fraction of the amount of weekly unemployment benefit they are entitled to. Workers benefiting from partial unemployment insurance are allowed to work for pay for any employer (including their past employers). In some specific circumstances workers whose hours have been reduced at their current workplace are eligible for partial unemployment insurance, so long as they can file a claim based 
on an employer certified reduction in hours worked. In practice, according to Le Barbanchon (2015), claimants with reduced hours represent a small share of total partial unemployment insurance. In addition, our empirical analysis shows the flows of worker from unemployment to involuntary part-time are very small and play a negligible role in the dynamics of involuntary part-time employment.

The final program that may offer income assistance to involuntary part-time workers are staterun short-time compemsation schemes. The basic idea behind these programs is that workers whose employers submit approved work-sharing plans are potentially entitled to unemployment insurance benefits. In priciple, the amount of benefits is prorated based on the reduction in hours. According to Abraham and Houseman (2014), these programs may be used for workers whose hours have been reduced by between $10 \%$ and a maximum determined by state law, which has to be below $60 \%$. The maximum duration for benefit reception is between six and twelve months, and they have a similar effect on employers' tax rates as unemployment benefits paid to laid-off workers. ${ }^{35}$ In practice, the scope of short-time schemes in the U.S. contex is limited (only about 15 states had such type of programs in place before the Great Recession). Although more states adopted those schemes during the recession and its aftermath, take-up rates in those states are still very small. For example, at the peak of the recession (2009), $0.22 \%$ of all employed workers in those states benefited from such scheme.

\section{D.2 International evidence on involuntary part-time employment}

The source of information for our analysis is aggregate data collected from the OECD's Annual Labor Force Survey. ${ }^{36}$ Specifically, we collected annual series of country-specific unemployment, part-time and involuntary part-time employment rates starting in 1994 until today. The sample details are summarized in Table C5. Inspection of the right-most column shows that, rather than a single definition of involuntary part-time work across countries, there are three or four different ones. Given the limited scope of our analysis we ignore those differences when making cross-country comparisons. To our best knowledge, there is no international hamornized definition of involuntary part-time work we could use instead. In light of the prevalence of involuntary part-time work, developing such a measure would be useful to obtain a richer characterization of labor market slack. The US and the UK's official statistical agencies produce different measures of labor market slack combining information on different categories of unemployment and underemployment. Doing so could also prove important to improve our understanding of cross-country differences in the provision of public insurance against the reduction in working hours. Unlike the US, in many European countries short-time compensation schemes were intensively used during the Great Recession, thereby providing some income insurance to workers whose firms' reduced working hours (see Hijzen and Venn, 2011).

Figure B2a plots countries' contemporaneous correlation between the unemployment rate and the involuntary part-time employment rate against their average involuntary part-time employment rates. The horizontal axis shows that the average involuntary part-time rates vary from just below $1 \%$ to just

\footnotetext{
${ }^{35}$ According to Abraham and Houseman (2014), some states impose surcharges on employers, and even prohibit employers with negative balances in their unemployment insurane accounts from implementing a short-time compensation plan.

${ }^{36}$ The data are available on-line from www.stats.oecd.org. The variable definitions are available from OECD (2015) and from the European Labor Force Survey.
} 
Table C5. Sample period and definition of involuntary part-time work

\begin{tabular}{lcl} 
Country & Sample & Measure of involuntary part-time employment \\
\hline Australia & $1994-2014$ & Would like to work more hours \\
Austria & $1995-2013$ & Could not find a full-time job \\
Belgium & $1994-2013$ & Could not find a full-time job \\
Canada & $1994-2013$ & Would like to work more hours; could not find a full-time job \\
Czech Republic & $1998-2013$ & Could not find a full-time job \\
Denmark & $1994-2013$ & Could not find a full-time job \\
Estonia & $2005-2013$ & Could not find a full-time job \\
Finland & $1996-2013$ & Full-time work is not available \\
France & $1994-2012$ & Could not find a full-time job \\
Germany & $1994-2013$ & Could not find a full-time job \\
Greece & $1994-2012$ & Could not find a full-time job \\
Hungary & $1998-2013$ & Could not find a full-time job \\
Ireland & $1994-2013$ & Could not find a full-time job \\
Israel & $1995-2013$ & Could not find a full-time job \\
Italy & $1994-2013$ & Could not find a full-time job \\
Japan & $1994-2012$ & Would prefer to work more hours \\
Luxembourg & $1994-2014$ & Could not find a full-time job \\
Netherlands & $1994-2013$ & Could not find a full-time job \\
New Zealand & $1994-2013$ & Would prefer to work more hours \\
Norway & $1994-2013$ & Would prefer to work more hours; could not find a full-time job \\
Poland & $2001-2013$ & Could not find a full-time job \\
Portugal & $1994-2013$ & Could not find a full-time job \\
Slovak Republic & $1994-2013$ & Could not find a full-time job; slack work \\
Slovenia & $2005-2013$ & Could not find a full-time job \\
Spain & $1994-2013$ & Could not find a full-time job \\
Sweden & $1994-2013$ & Would like to work more hours; could not find a full-time job \\
Switzerland & $1994-2013$ & Could not find full-time job \\
Turkey & $2009-2014$ & Not available \\
United Kingdom & $1994-2013$ & Could not find a full-time job \\
United States & $1998-2014$ & Could not find a full-time job; slack work \\
& & \\
& & \\
\hline
\end{tabular}

NoTE: For Canada and Sweden, involuntary part-time employment also includes the following category: "believes full-time work not available". 
below 7\%, underscoring the extent and prevalence of this phenomenon in all sampled countries. Inspection of the vertical axis indicates that cyclical patterns are not uniform across countries (in some of them the correlation coefficient is negative and significant), but for the majority of countries there is a positive and significant association betwen the two rates. This suggests that involuntary part-time rate is important to understand the impact of the business cycle on the labor market. Interestingly, and consistent with one of the premises of the paper (that involuntary part-time and voluntary part-time constitute very distinct labor market states), there is none, or a very limited, apparent statistical relationship between a country's aggregate part-time employment rate and its involuntary part-time rate. This can be seen in Figure B2b, which plots countries' average involuntary part-time employment rates (y-axis) against their part-time employment rates (x-axis). It is also visible that mean part-time employment rates vary widely across countries (between 2 and 34\%), in contrast to mean involuntary part-time rates (between 1 and 7\%). 


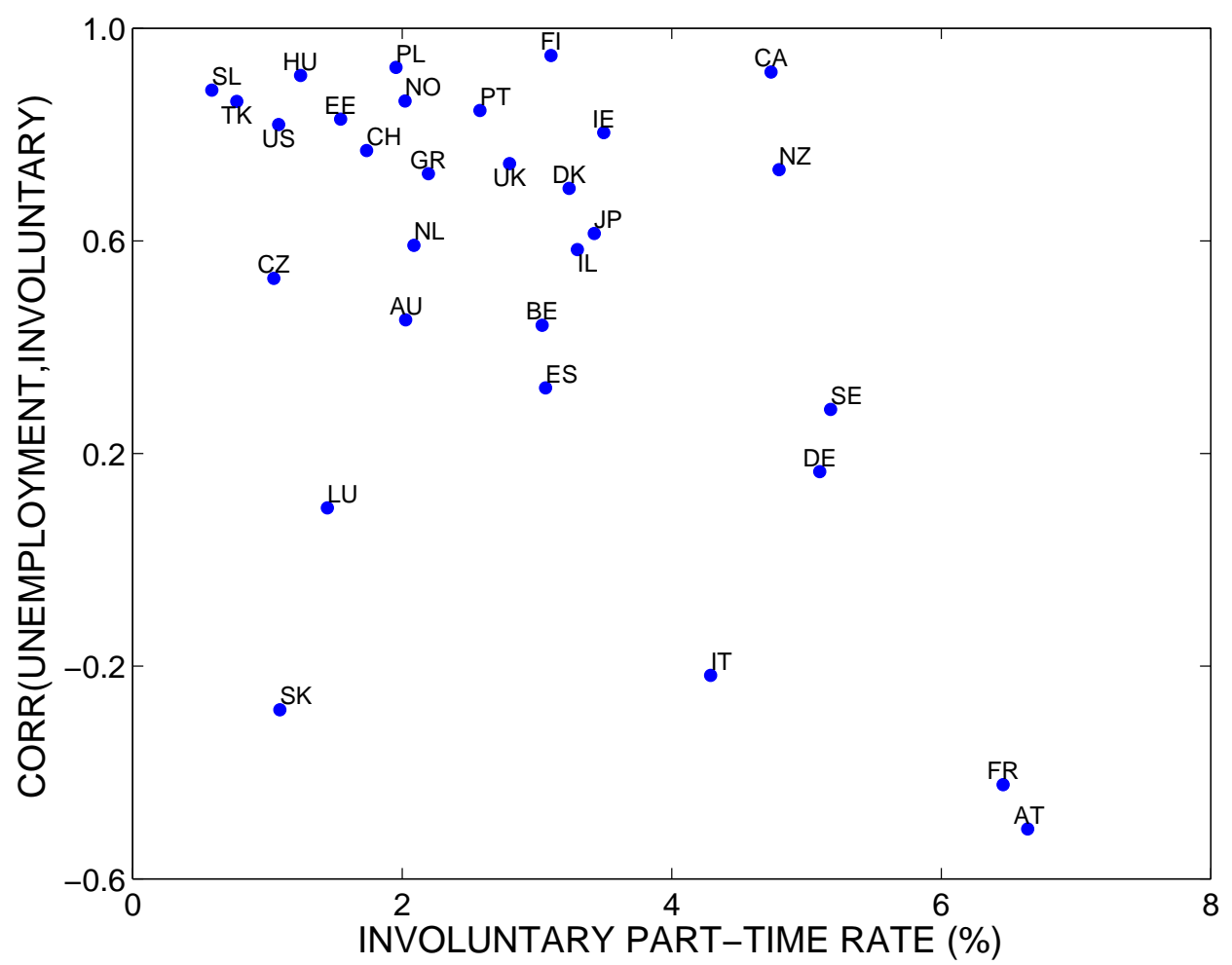

(a) Involuntary part-time work and unemployment

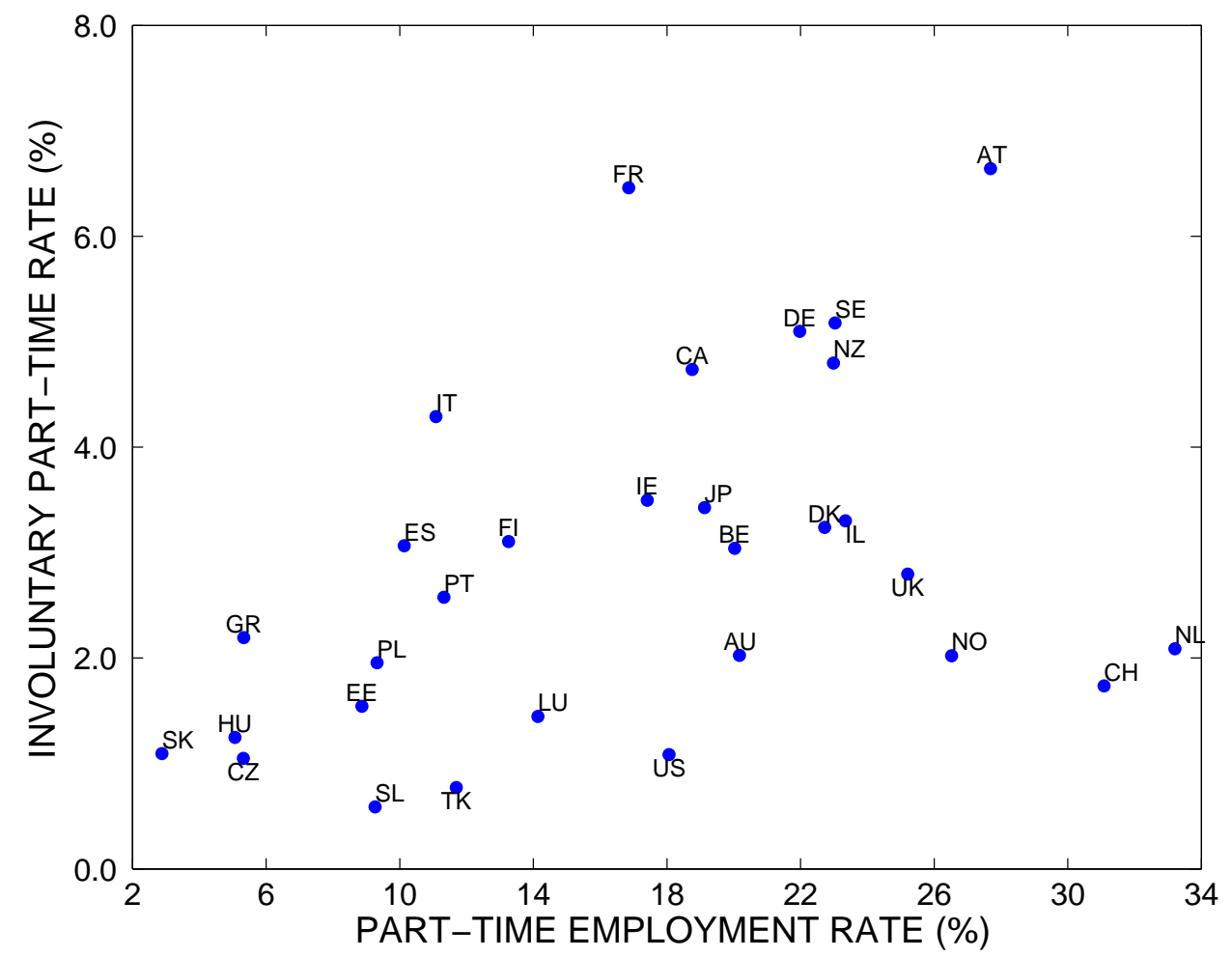

(b) Involuntary part-time work and overall part-time work

Figure B2. Involuntary part-time employment: Cross-country evidence Data from the OECD Annual Labor Force Survey. See text for the variable definitions. 


\section{References}

Aaronson, Daniel, and Eric French. 2004. "The effect of part-time work on wages: Evidence from the Social Security rules." Journal of Labor Economics, 22(2): 329-252.

Abdulkadiroğlu, Atila, Burhanettin Kuruşçu, and Ayşegül Şahin. 2002. "Unemployment insurance and the role of self-insurance." Review of Economic Dynamics, 5(3): 681-703.

Abraham, Katharine G, and Susan N Houseman. 2014. "Short-time compensation as a tool to mitigate job loss? Evidence on the US experience during the recent recession." Industrial Relations: A Journal of Economy and Society, 53(4): 543-567.

Acemoglu, Daron, and Robert Shimer. 2000. "Productivity gains from unemployment insurance." European Economic Review, 44(7): 1195-1224.

Barrett, Garry F, and Denise J Doiron. 2001. "Working part time: By choice or by constraint." Canadian Journal of Economics, 34(4): 1042-1065.

Blanchflower, David G, and Andrew T Levin. 2015. "Labor market slack and monetary policy." NBER Working Paper 21094.

Borowczyk-Martins, Daniel, and Etienne Lalé. 2014. "Employment adjustment and part-time jobs: The US and the UK in the Great Recession." Sciences Po Discussion paper 2014-17.

Braun, Helge, and Björn Brügemann. 2014. "Welfare effects of short-time compensation." IZA Discussion Paper No. 8597.

Burdett, Kenneth, and Randall Wright. 1989. "Unemployment insurance and short-time compensation: The effects on layoffs, hours per worker, and wages." Journal of Political Economy, 97(6): 1479-96.

Cahuc, Pierre, and Stéphane Carcillo. 2011. "Is short-time work a good method to keep unemployment down?" Nordic Economic Policy Review, 1(1): 133-165.

Cajner, Tomaz, Dennis Mawhirter, Christopher Nekarda, and David Ratner. 2014. "Why is involuntary part-time work elevated?" FEDS Notes.

Darby, Michael, John Haltiwanger, and Mark Plant. 1986. "The ins and outs of unemployment: The ins win." NBER Working Paper 1997.

Elsby, Michael WL, Bart Hobijn, and Ayşegül Şahin. 2015. "On the importance of the participation margin for labor market fluctuations." Journal of Monetary Economics, 72: 64-82.

Fernández-Blanco, Javier. 2013. "Labor market equilibrium with rehiring." International Economic Review, 54(3): 885-914.

Fujita, Shigeru, and Garey Ramey. 2009. "The cyclicality of separation and job finding rates." International Economic Review, 50(2): 415-430. 
Fujita, Shigeru, and Giuseppe Moscarini. 2013. "Recall and unemployment." NBER Working Paper 19640.

Gourinchas, Pierre-Olivier, and Jonathan A Parker. 2002. "Consumption over the life cycle." Econometrica, 70(1): 47-89.

Gruber, Jonathan. 1997. "The consumption smoothing benefits of unemployment insurance." The American Economic Review, 87(1): 192-205.

Hansen, Gary D., and Ayşe İmrohoroğlu. 1992. "The role of unemployment insurance in an economy with liquidity constraints and moral hazard.” Journal of Political Economy, 100(1): 118-42.

Heathcote, Jonathan, Kjetil Storesletten, and Giovanni L Violante. 2009. "Quantitative macroeconomics with heterogeneous households.” Annual Review of Economics, 1(1): 319-354.

Hijzen, Alexander, and Danielle Venn. 2011. "The role of short-time work schemes during the 2008-09 recession.” OECD Social, Employment and Migration Working Papers no. 115.

Hirsch, Barry T. 2005. "Why do part-time workers earn less? The role of worker and job skills." Industrial \& Labor Relations Review, 58(4): 525-551.

Hotchkiss, Julie, and Randall Wright. 1988. "A general model of unemployment insurance, with and without short-time compensation." Research in Labor Economics, 9: 91-131.

Jones, Stephen RG, and W Craig Riddell. 1999. "The measurement of unemployment: An empirical approach.” Econometrica, 67(1): 147-162.

Kaplan, Greg, and Giovanni L Violante. 2014. "A model of the consumption response to fiscal stimulus payments.” Econometrica, 82(4): 1199-1239.

Krusell, Per, Toshihiko Mukoyama, Ayşegül Şahin, and Anthony A Smith. 2009. "Revisiting the welfare effects of eliminating business cycles." Review of Economic Dynamics, 12(3): 393-404.

Krusell, Per, Toshihiko Mukoyama, Richard Rogerson, and Ayşegül Şahin. 2015. "Gross worker flows over the business cycle." Mimeo, previously NBER Working Paper 17779.

Le Barbanchon, Thomas. 2015. "Optimal Partial Unemployment Insurance: Evidence from Bunching in the U.S."

Moscarini, Giuseppe, and Kaj Thomsson. 2007. "Occupational and job mobility in the US." The Scandinavian Journal of Economics, 109(4): 807-836.

Nichols, Austin, and Jesse Rothstein. 2015. “The earned income tax credit (eitc).” National Bureau of Economic Research.

OECD. 2007. "Benefit systems and work incentives.” OECD Indicators.

OECD. 2015. "Labor Force Statistics in OECD countries: Sources, coverage and definitions." 
Shimer, Robert. 2012. "Reassessing the ins and outs of unemployment." Review of Economic Dynamics, 15(2): 127-148.

Stratton, Leslie S. 1996. "Are "involuntary" part-time workers indeed involuntary?" Industrial \& Labor Relations Review, 49(3): 522-536.

Sum, Andrew, and Ishwar Khatiwada. 2010. "The nation's underemployed in the Great Recession of 2007-09." Monthly Labor Review, 133(11): 3-15.

U.S. Bureau of the Census. 2013. "Current Population Survey - Interviewing manual." Technical papers available at: https://www.census.gov/cps/.

Valletta, Robert, and Catherine van der List. 2015. "Involuntary part-time work: Here to stay?" FRBSF Economic Letters, 19.

Valletta, Robert, and Leila Bengali. 2013. "What's behind the increase in part-time work?" FRBSF Economic Letter, 24.

Yellen, Janet L. 2014. "Labor market dynamics and monetary policy." Remarks given at the Federal Reserve Bank of Kansas City Economic Symposium, Jackson Hole, Wyoming, August 22. 